\section{LA-8336-MS}

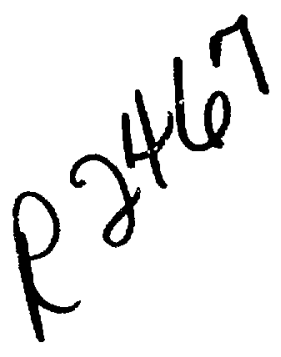

Criticality Calculations and Criticality Monitoring Studies of the Slagging Pyrolysis Incinerator Facility

$\frac{\sigma}{\frac{\sigma}{5}}$

$\pm$

$\frac{1}{2}$ 


\title{
Criticality Calculations
}

\section{and Criticality Monitoring Studies of the} Slagging Pyrolysis Incinerator Facility

\author{
D. A. Close \\ T. E. Booth \\ J. T. Caldwell
}

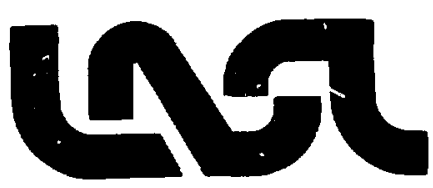




\section{CONTENTS}

ABSTRACT $\ldots \ldots \ldots \ldots \ldots \ldots \ldots \ldots \ldots \ldots \ldots \ldots \ldots$

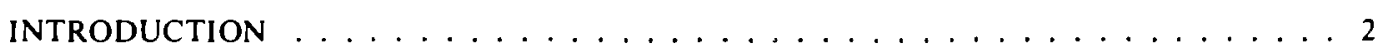

I. MONTE CARLO NEUTRON CALCULATIONS OF THE CRITICALITY HAZARD IN

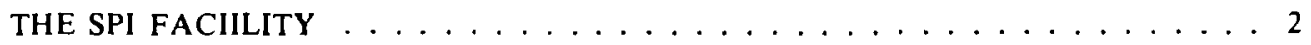

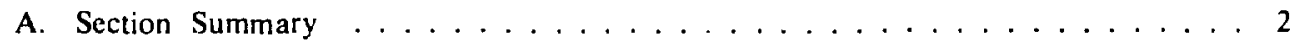

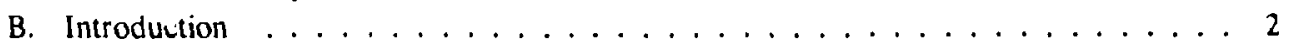

C. Brief Code Description .................... 3

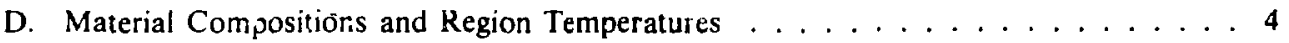

E. Incinerator Geometry . . . . . . . . . . . . . . . . 6

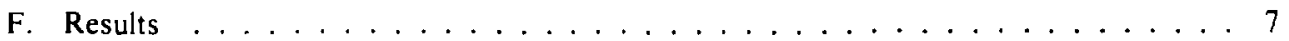

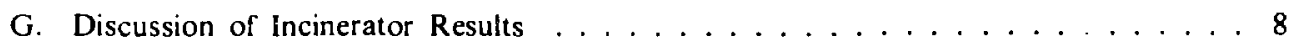

H. Secondary Combustion Chamber, Slag Tap, and Holding Tank . . . . . . . II

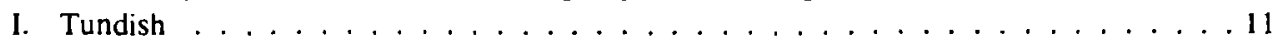

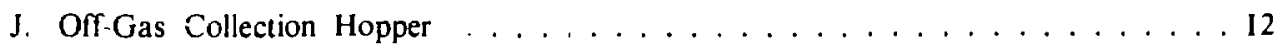

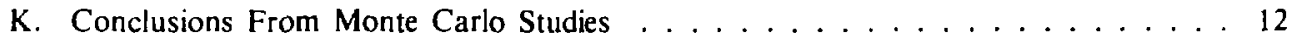

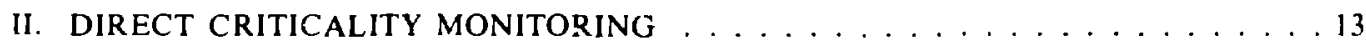

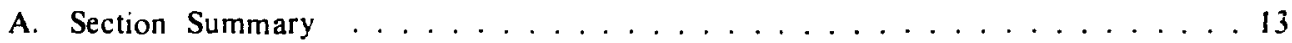

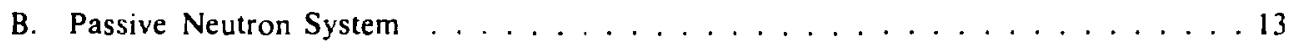

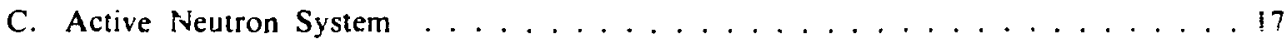

III. DISTINGUISHING BETWEEN FISSILE AND FERTILE MATERIALS IN NUCLEAR

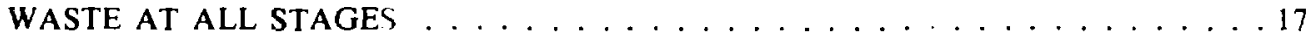

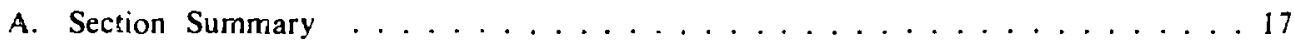

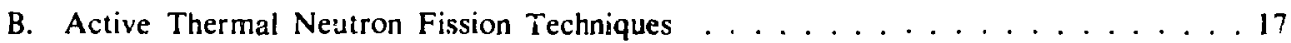

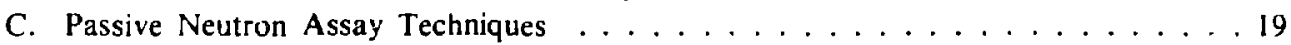



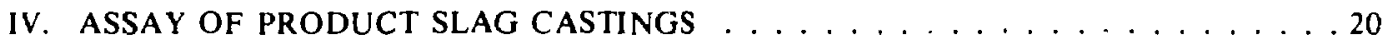

V. CONCLUSIONS, RECOMMENDATIONS, AND COST ESTIMATES . . . . . . 21

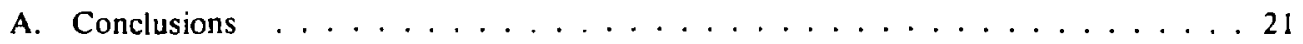

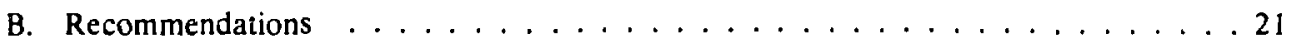

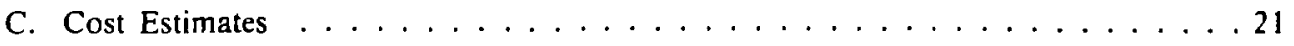

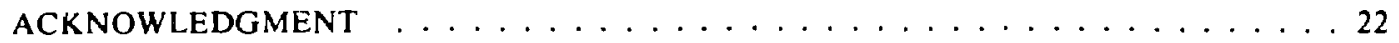

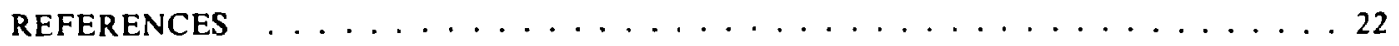






\title{
CRITICALITY CALCULATIONS AND CRITICAI.ITY MONITORING STUDIES OF THE SLAGGING PYROLYSIS INCINERATOR FACILITY
}

\author{
by
}

\author{
D. A. Close, T. E. Booth, and J. T. Caldwell
}

\begin{abstract}
We determined that the criticality hazard associated with the Slagging Pyrolysis Incinerator (SPI) Facility proposed by Idaho National Engineering Laboratory would be minimal if a three-level criticality-hazard prevention program were implemented. The first strategy consists of screening all incoming wastes for fissile content. An estimate of the average fissile content of wastes to be processed by the SPI Facility is $\leq \mathrm{lg}$ fissi.e per $50 \mathrm{~kg}$ waste. Monte Carlo calculations indicate that under normal operating conditions this average fissile concentration poses no criticality hazard. A fissile concentration in the SPI Facility ten times this average value is required to produce $k$ of about 0.4 . Large lumps are not allowed to enter the system, which effectively prevents a rapidly developing criticality hazard. Suitable instrumentation to easily and reliably accomplish this screening/assay is currently under development at both EG\&G, Inc. and Los Alamos Scientific Laboratory.

The second prevention level is provided by introducing a small concentration of a neutron-absorbing compound, such as $\mathrm{B}_{2} \mathrm{O}_{3}$, into the input waste stream. Our Monte Carlo calculations showed, for instance, that including only $1.0 \times 10^{2} \mathrm{wt}$ fraction of $B, O$, reduces the criticality hazard to a negligible level.

Example: For $9.3 \mathrm{~kg}{ }^{234} \mathrm{Pu}$ in the drying legion without $\mathrm{B}_{2} \mathrm{O}_{3}, \mathrm{k}=0.99$. For the same $9.3 \mathrm{~kg}$ of ${ }^{239} \mathrm{Pu}$ in the drying region with $1.0 \times 10^{-2}$ wt fraction of $\mathrm{B}_{2} \mathrm{O}_{2}$. added, $k=0.24$.

Tire third prevention level is provided by direct criticality-hazard monitoring using sensitive neutron detectors in all regions of the facility where a significant hazard has been identified-principally the drying, pyrolysis, and slag regions. These detectors can be operated in a passive mode or can be used with a pulsed external neutron source to obtain a direct measure of $k$. These neutron detectors have been used in other applications to measure $k$ in the range 0.05 to 0.10 . They can also be used to determine an approximate value of the total fissile mass in the SPI Facility. On the basis of this data, the facility could be shut down rapidly for cleanout if these measurements indicate an unsafe condition is developing. The criticality safety provided by the product of these three independent measures should reduce the hazard to a negligible level. We recommend that they be implemented in the SPI Facility. A detailed fault tree statistical analysis should be done to quantify the safety factors associated with each of the three levels of this criticality hazard prevention program. Such an analysis is beyond the scope of this report.
\end{abstract}




\section{INTRODUCTION}

The Los Alamos Scientific Laboratory (LASL) study of the proposed Slagging Pyrolysis Incinerator (SPI) Facilty for criticality hazard and for appropriate criticality monitoring was initiated at the request of EG\&G, Inc.. Idaho $F$ alls, Idaho. LASL agreed to independently study the problem of criticality hazard in the SPI Facility and to recommend, on the basis of this study. appropriate criticality monitoring instrumentation and/or procedures to mininize or lessen potential criticality hazards.

Specific analyses for this study included the following.

1. A Monte Carlo neutron study was performed to(1) examine :he effects of neutron poisoning and various typical matrix materials on criticality, as well as their effects on possible eriticality-monitoring systems: (2) identify areas of the SPI Facility where criticality hazards exist: and (3) quantify the hazarrs as much as possible. Specifically. we addressed the problems as sociated with piutonium lumps being processed through the system and quantified the criticality hazards as sociated with plating out of plutonium in various regions.

11. A study of direct criticality monitoring techniques and equipnent included both active and passive neu tron hased methods, with a limited rumber of experimen tal measurements on multiplying systems. Recommenda tions of the approprate technique(s) with estimates of needed development and associated costs were included.

III. The general problem of eistnguishing betueen fissile and fertile marerials in waste both before and after slagging uas studied.

IV. Methods for assaying product slag in $91.44 \mathrm{~cm} / 36 \mathrm{in}$. 1 diam $\times 30.48 \mathrm{~cm}(12 \mathrm{~m}$.) thick ingots were studied.

\section{MONTE CARLO NEUTRON CALCULATIONS OF THE CRITICALITY HAZARD IN THE SPI FACILITY}

\section{A. Section Summary}

Monte Carlo calculations were performed to de termine critical plutonium concentrations $i_{2}$, various regions of the proposed SPI Facility. The incinerator was divided into three plutonium containing regions: the drying. pyrolysss, and slag regions. Calculations in. dicated that these regions are only weakly cuupled neutronically: that is, when each region by itself is close to critical, the whole incinerator remains close to critical. The critical plutonium weight fractions for the drying. purolysis. and slag forming regions are $3.0 \times 10^{3} .2 .6 \times$ 10 '. and $2.0 \times 10^{\prime}$ '. respectively. These weight fractions translate into ${ }^{234} \mathrm{Pu}$ critical masses of 9.3. 28.7. and 271 $\mathrm{kg}$, respectively: In other words. the minimum critical mass of "Pu for the SPI Facility as a whole is $9.3 \mathrm{~kg}$ if the entire $4.3 \mathrm{~kg}$ is placed within the drying region.

Linder somc operating conditions, fissile material build up within the SPI Facility is possible. In this situation. a criticality hazard could potentially develop even though onlv average fissile content waste $u$ as being processed. A strategy to lessen this hazard is to mix a small amount of neutron absurbing material into the waste. Calculations indicated. for example. that $1.0 \mathrm{x}$ $10^{2}$ wt fraction of $\mathrm{B}_{2} \mathrm{O}$, mixed with the waste greatly reduces the criticality hal $z$ ard associated with any given fissile inventory. This fraction of $\mathrm{B}_{2} \mathrm{O}$, uniformly mixed with an otherwise eritical concentration of plutonium in the drying region reduces $k$ to about 0.24 . a reasonatly safe value. In fact. a sinvilar strategy is used roumelo 10 prevent criticalty hazards in fissile containng solutions. Here neutron absorption is provided by placing borosilicatc glass "raschig" rings within the soluti:nn."

Such dramatic effects might not he obtaned under all

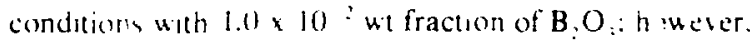
it is cleat that this simple procedure produces a highly cost elfectle reduction in overall criticality hiszart. !n contrast. designing boron thio the gastier siructure tise it do's not have a large effect on critcalty. Caliu lationally. $h$, of the hearth regron drops from $1.00 \% 0.76$ when the firebrick is totally replaced with natural elemental horen.

Calculations modicated that fissile lumps tad-ilitis (ratively detined as single inclusions of $\geq 200 \mathrm{~g}$ tissile) can produce a rapidly developing criticalit! hazard. A single $20(1)$ lunp of high density "PuO, cari result in $\mathrm{k}$ of 0.21 . whercas the same ${ }^{24} \mathrm{PuO}$, mass spread unifiornIy throughout the drying region produces $k$ about 0.05 . Fissile lump thould now be processed in the SPI Factlity beciause they could concervabiy lead to a raphl! de reloping crillcality hatard.

\section{B. Introduction}


Natunal Enquecring Laboratury (INAt:L) for prexcosing their stored transuranic (TRL) uasic. figure 1 is a 


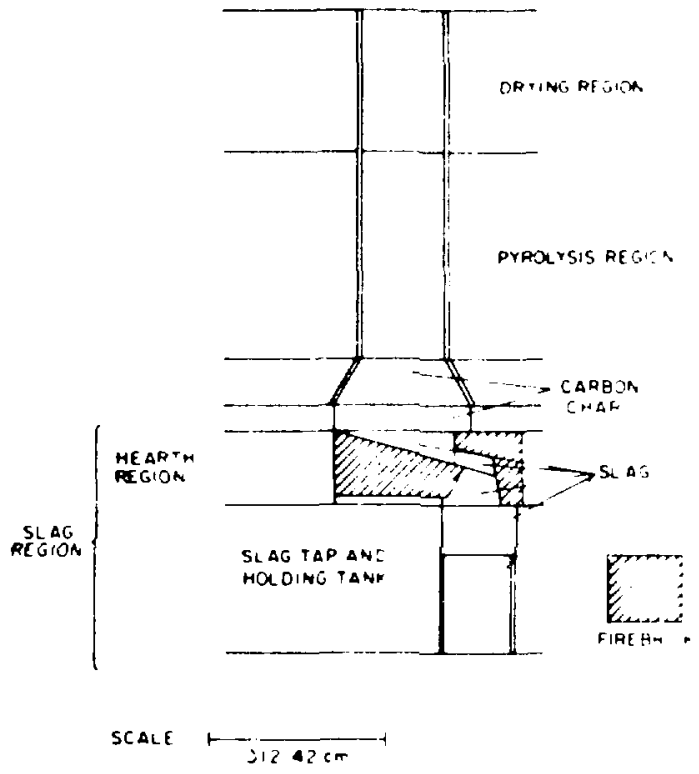

Fig. 1.

Calculational geometry of the SPI. showing ihe $y$ plane at $x$ 0 . Shown are the drying. pyrolysis, and slag regions. The slag region is composed of (wo) smaller regions the hearth region and the slag tap and heiding tank.

simplified drawing of the incinerator that is used for calculational purposes. The plutonium coniaminated wastes enter the incinerator in the drying region, pass, through the pyrolysis region. and then enter the slag region where the wastes are heated to a molten mass This incinerator model was studied for criticality haz ards.

These extensive Monte Carlo ealculations used LASL's Monte Carlo code for neutron anu photon transport (MCNP):" Specitically. MCNP was used to calculate $k$ of the incinerator. The $k$ of a system is defined as the multiplication fattor of the system. The different regions of the incinerator-drying. pyrolysis. and slag-were studied individualy and as a total system. The $k$ of each of the three regions was calculated as a function of the ${ }^{: 14} \mathrm{Pu}$ concentration. As discussed below, the drying region of the incinerator has the lowest critical mass of ${ }^{234} \mathrm{Pu}$ of the three regions. For this region, the effect of neutron poisons, namely boron in the form $\mathrm{B}_{2} \mathrm{O}_{1}$, on $\mathrm{k}$ of this region was studied. Another specialized case studied was the build up of a layer of ${ }^{234} \mathrm{PuO}$, on the walls of the drying and pyrolysis regions. The input material to the SPI Facility even after scremng could concessably contain $200 \mathrm{~g}$ lumps of "PuO.. The effiet of such a lump of ${ }^{219} \mathrm{PuO}_{2}$ in the dryng regon on $k$ of the region was calculated also.

Part of our arralysis of the SPI Facility included possible methods for menitoring the neutron activity in the mimerator. Additonal neutronic calculations mod. eled neutrom detectors surrounding the incinerator to determine the effect of increased moderation resulting from ine neutron dececors.

Imtai parameter siudes indicated the SPI Facility had a postuc temperature coefictent: $k$ increases as the temperature increases. The final series of calculations for the incunerattor determuned the variation of $k$ on the comperiture at the dring region. a not insignticant ellect

Jhece eccondary structures associated with the SPI Facilaly were also studied. These were the secondary combustion shamber. Jag tap. and holding tank: the tundisti. and the aff gas collection hopper.

All calculatuns uere pertormed assuming plutonium to he the fissle material. Thes is justified because the :nckipaled amount of highly enriched uranium to he processed hi the SPI Facilit! is a small fractuon of the anticipated amount of plutomum to be processed. All wher parameters heing equal, the critical mass, concen tralwn. or whtume of " $\mathrm{Pu}$ is less than or equal to that for ': L'. I hus. results obthed for plutonsum trans late mte correnonding consers ative "L or "L results.

\section{Brief Code Description}

The general purpose MC NP: code can be used for neutron. photon. ur coupled neutron photon transport. which include: the capability to calculate eigenvalues of critcal ytenis. The code treats an arbitrary three dimensimal sontiguration of materials in geometric cells that can be specified by first and second deree surtices and some special fourth degree surfaces lellip lical (ur)

Pointulse iross section data are used. For neutrons. all reactions guen in a particular cross section eval uation fsuch a FNDF $B$ IV ) are accounted for. Thermal neutrons are described by both the free gas and $\mathbf{S}(\boldsymbol{\alpha}, \boldsymbol{\beta})$ models. For photons. the code takes account of incoherent and coherent scattering. the possibility of fuoresient emission following photoelectric absorption. and absorption in pair production with local emission of annihilaton radiaton. 
Standard features that are available to improve com putation efficiency include geometry splitting and Rus sian roulette. weight cut off with Russian roulette. cor related sampling. analog capture or capture by weight reduction. exponential transformation, energy splitting. forced collisions in designated cells, fiux estimates at point or ring detectors. deterministically transporting pseudo particles to designat ed regions. track length estimators, source biasing. and several parameter cutoffs.

Fxtensive summary information is provided in the computer listing to help the user better understand the physics and Monte Carlo simulation of his probiem. The standard. user jeiined output of MCNP includes Ino way current as a function of direction across any set ui surfaces or surface segments in the problem. Flux across an! set of surfaces or surface segments is computed. Similarly, the flux at designated detectors and the average flux in any cell (track length per unit volume) are standard tallies. Reactions such as fission. tritium productuon. absorption. or any product of the hux times any standard FNDF reaction cross section plus several nonstandard ones may be obtained in any cell. at a urface, or at a point. The heating tallies give the energy deposition in desiznated cells. In addition. particles may be flagged when they cross specified surfaces or enter designated cells. and the contributions of these flagged particles to the tallies are listed separately. The user is allowed to modify any of the standard tallies almost at will. All quantuties tallied also have their relative errors calculated. All talles are a function of tume and energy as defined by the user

MCNP has the capabilit! to calculate eigentalues for both sub and supercritical systems. The calculation is run as a series of generations of neutrons. At the end of each generation. $k_{\mathrm{eff}}$ is calculated for that generation as uell as averaged over a specified number of preceding generations. The source for the first generation is usually defined by the user at a set of spatial points in the system. The neutrons are then started isotropically at these points with an energy sampled from standard fission distributions.

The cross sections used were taken from several sources. If an ENDF/B cross-section file was available for the isotope of interest. it was chosen as the preferred cross section. Some of the ENDF/B cross section files were version 111 and some were version IV. Alte. sasive cross section files were taken as needec from LLL Howerton.

\section{Material Compositions and Region Temperatures}

Table. I VI list the elemental compositions of the materials in the different regions of the incinerator and the secondary structures. All elemental compositions are given as weight percentages. The elemental composition of the material in the drying region' is listed in Tabie $I$. The density of this material is $0.706 \mathrm{~g} \cdot \mathrm{cm}^{\prime}$. The material in the pyrolysis region 'has a density of $1.76 \mathrm{~g} \mathrm{~cm}^{3}$, and its elemental composition is presented in Table 11. The slag material is common to the slag region (hearth. slag tap. and holding tank) of the incinerator: the secondary combustion chamber. slag tap. and holding tank: and the tundısh. The slag has a density of $2.80 \mathrm{~g} \mathrm{~cm}^{\prime}$, and $\mathrm{th}$ elemental compostion 'is given in Table III. A large fraction of the external surface area of the slite forming regan in the incinerator is surrounded by firebrich There is also firebnck surrounding the slag ir: the secondaiy combustion chamber, slag tap. and holumg tank. and in the tundish. The elemental compostion of the firebrek. ' wheh has a density of $2 .{ }^{-} 0 \mathrm{~g} \mathrm{~cm}^{\prime}$. M istic: in Table IV. The conpostion of type 316 stanless stec: on the cutulfe of the tundish and surrounding the off gas collectuon hopper is presented in Table V. The ciemental compxutuon of the material in the off gas colicuiom hopper is gaven in Tahle VI. One of the compounde ir: this materal uas a trace metal oxide. which we ass'med to be stainless steel. knowing plutonium contammated stainless stecl would be par of the feed material for the SPI Facillt:

None of the abose tables indicates the presence of plutonum. The plutwiltm coilcentration. expressed as a weight percentagc. was a a ariable. and differen: anounts were added tw the dring. pyrolysis. slag. and off gas collecton materals

Except for the staunless steel. none of the materia: compositions adds to $1(10 \% \%$. This is becatise the informi tion prowited us dad not add to $100 \%$ and bocaluse the plutonium concentration is not included in the tables

Another parameter needed by MCNP is the icm perature of each material and region. At elevated tem neratures. neutron resonances become wider because of Doppler broatening effects. Such an effect changes the neutron interaction cross section. Because of relatively high temiperatures in the slag and the lirebrick. It was deemed advisitite w use approprate temperatures. The temperatures provided by INEL tor the different regions of the incinerator and for the secondary structures are presented in Table' VIll. 
TABLE I

DRYING REGION MATERIAL ELEMENTAL COMPOSITION ${ }^{a . h}$

\begin{tabular}{lr} 
Element & Weight Perce \\
\hline & \\
H & 4.99 \\
$\mathrm{C}$ & 25.10 \\
$\mathrm{O}$ & 48.54 \\
$\mathrm{Na}$ & 0.57 \\
$\mathrm{Al}$ & 1.62 \\
$\mathrm{Si}$ & 8.15 \\
$\mathrm{~S}$ & 0.80 \\
$\mathrm{Ca}$ & 2.02 \\
$\mathrm{Fe}$ & 6.86 \\
& -88.65
\end{tabular}

Demsit! $0.700 \% \div \mathrm{cm}$ Rel. 3.

TABLE II

PYROLYSIS REGION MATERIAL ELEMENTAL COMPOSITION ${ }^{a, h}$

\begin{tabular}{cr} 
Element & Weight Percent \\
\hline & \\
$\mathrm{H}$ & 3.53 \\
$\mathrm{C}$ & 1.41 \\
$\mathrm{O}$ & 42.30 \\
$\mathrm{Na}$ & 1.41 \\
$\mathrm{Mg}$ & 1.06 \\
$\mathrm{Al}$ & 4.23 \\
$\mathrm{Si}$ & 21.20 \\
$\mathrm{~K}$ & 1.41 \\
$\mathrm{Ca}$ & 5.29 \\
$\mathrm{Ti}$ & 0.03 \\
$\mathrm{Mn}$ & 0.46 \\
$\mathrm{Fe}$ & 17.60 \\
& 99.93 \\
\hline
\end{tabular}

Density $1.76 \mathrm{~g} / \mathrm{cm}^{\prime}$

Rer. 3.
TABLE III

SLAG REGION;

SECONDARY COMBUSTION CHAMBER, SLAG TAP, AND HOLDING TANK; AND TUNDISH MATERIAL. ELEMENTAL COMPOSITION"in

\begin{tabular}{|c|c|}
\hline Flement & Weight Percent \\
\hline ( & 1.311 \\
\hline () & 45.80 \\
\hline$V_{i l}$ & 1.41 \\
\hline$M_{g}$ & 1.04 \\
\hline 11 & 4.12 \\
\hline $\mathrm{Si}$ & 21.10 \\
\hline $\mathbf{k}$ & 1.32 \\
\hline ('i) & 5.20 \\
\hline $\ln$ & 0.50 \\
\hline \multirow[t]{2}{*}{$r \cdot e$} & 17.90 \\
\hline & 94.64 \\
\hline
\end{tabular}

'Demils 2.81) gecm Rat ?

IABI I. II

HIRHBRICK HIIMINTAI COMPOSIIION"

I.kment

Weight Percent

()

Vil

49.70

0.74

$M_{t}$

0.60

(1)

20.10

$\mathrm{Si}$

26.30

(a)

0.71

$\mathrm{Ii}$

120

I.e

0.71

100.06

IDensit! $2.76 \mathrm{E} / \mathrm{cm}$

"Ret ? 
TABLE $V$

\section{TYPE 316 STAINLESS STEEL ELEMENTAL COMPOSITION*}

Element

\begin{tabular}{cr}
$\mathrm{Cr}$ & 18.5 \\
$\mathrm{Fe}$ & 68.5 \\
$\mathrm{Ni}$ & 13.0 \\
& 100.0 \\
\hline "Densit! $8.02 \mathrm{~g} \mathrm{~cm}$ &
\end{tabular}

TARI.E VI

\section{OFF GAS COLLECTION HOPPER MATERIAL FLFMENTAL COMPOSITION}

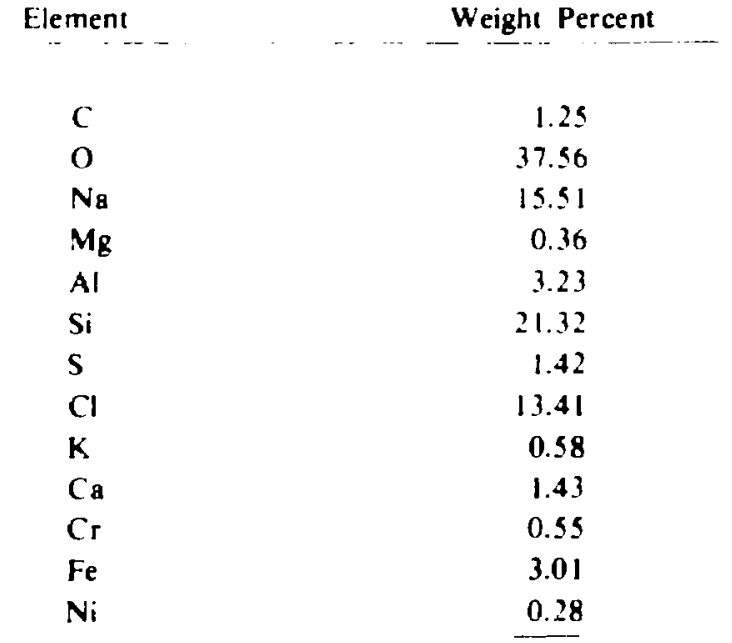

99.91
'Demity $1.28 \mathrm{~g} \mathrm{~cm}$

Ret. 4.

\section{E. Incinerator Geometry}

Figure $I$ is a view of the incinerator ${ }^{4}$ as modeled for the MCNP criticality calculations. Labeled are the drying. pyrolysis, and slag regions. The slag region includes the hearth region and the slag tap and holding tank. The hearth region contains the burners and is almost totally surrounde $d$ by firebrick. The area between the hearth and the pyrolysis regions is filled with
TABLE VII

\section{TEMPERATURE OF REGIONS OF INCINERATOR ${ }^{\text {A }}$}

$\begin{array}{lr}\text { Region } & \begin{array}{r}\text { Temperature } \\ (\text { C) }\end{array} \\ \text { Drying } & 1000 \\ \text { Pyrolysis } & 1000 \\ \text { Slag } & 1482 \\ \text { Firebrick } & 1260 \\ \text { Water Jachet } & 66 \\ \text { Tundish } & 1482 \\ \text { Secondary Cumbustion } & \\ \text { Chamber } & 1482 \\ \text { OTt Gas Coliection Hopper } & 149 \\ \text { Rut. } 4 & \end{array}$

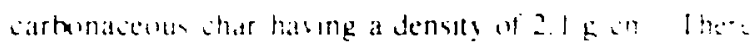

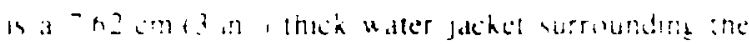



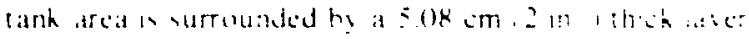
wh tirchrick and a $2.54 \mathrm{~cm}$ (1) in. I thick water jacke" I ta:

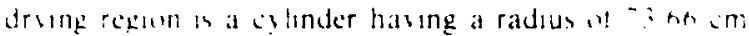

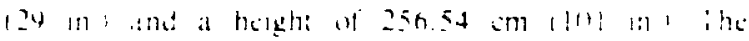

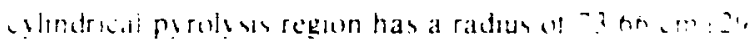

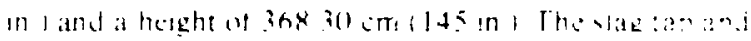



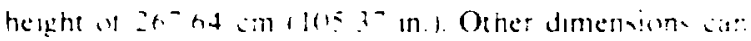

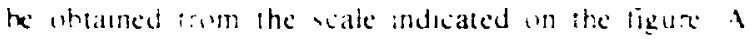

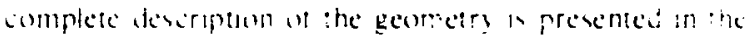
Apperidix

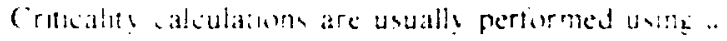
greath ympitied geenetry. replacung compilicated - Ir .

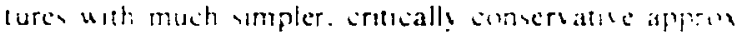
imattory Ihe approach was not used in this analyo An aciurate geometrical model uas ued for the entre SPI Fachlin! Ihes analysis should more accurately

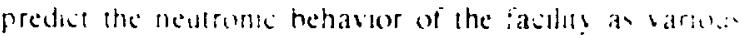
neutrome perturhation are appled to the meineratur fi must he emphassed that this 1 a sery complisatei geometrs for $\mathbf{M C} \mathrm{NP}$ calculatons. Corsicierahle compulet ume a required to obtain a converged source

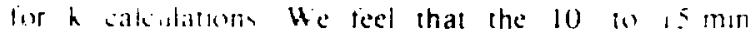

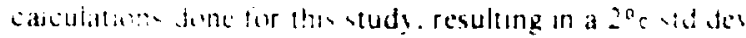

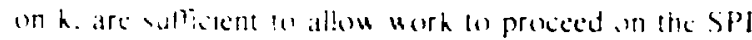
Facilus However. several 1 to $2 \mathrm{~h}$ calculations should be done when the plans are complete to obtain a beller 
TABLE VIII

\section{SPI FACILITY K CALCLLATIONS}



$\begin{array}{cc}1 & \therefore \\ 0+4 & \therefore \\ 0-4 & \text { is } \\ 049 & \because 4 \\ 110 & \text { in } \\ 1140 & \end{array}$

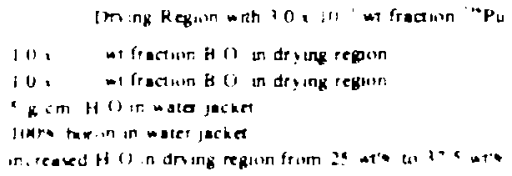

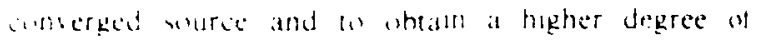
andideracenthe renith

\section{r. Results}

[he rewle of the we sp k alculation are presented


were made associated whth them. ('ases) 1 s gree the variation of $h$ with plutomum somecneratum on the dryeng regun of the incineratur the sasulaturn in (a) 5 was made using

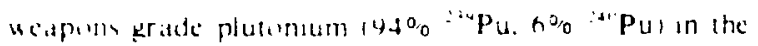
dry7g regun. Ih. varlation of h with the plutonum

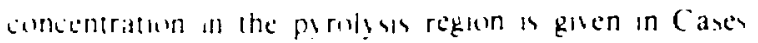
h 4 Studer whe the regun. slag tap and holding tank. and nearth regan are summarsed in Cases 1020. Included on these shag regun studies are the effects of

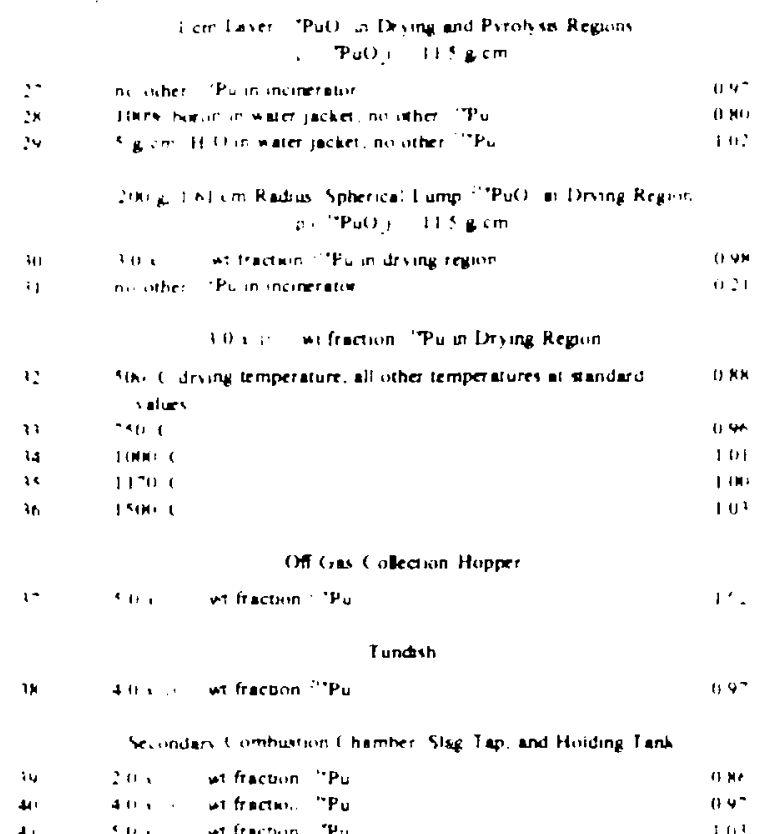

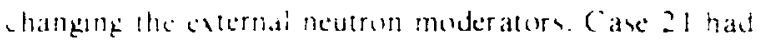



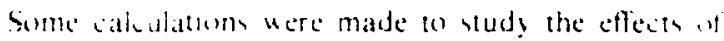
addme nevtron athorhing materal to the feed mixture on the crichat concentratums of : "Pu. These studies werc done ouly for the mont critcally senstuve region. the drumg rékm. and are summarmed in Cases 22 and 23 The effect il cxlernal neutron moderaters on the neti irunces of the dreung regun is listed in Caxes 24 and 25. ( asc zh indates what happens to $k$ when the amount of water w the atrumg regun is increased from 25 to 3.5

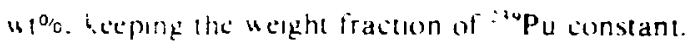

A portential monstandard operating situation is the huld up of a laser of plutorium on the inside surface of the drstug and pyralyss regons. A very conservative estumate "ar made assumng this layer to be ${ }^{214} \mathrm{PuO}$, of densit? $11.5 \mathrm{~g} \mathrm{~cm}$. The results of the calculations for a layer of "PuO, are presented in Cases 2729. 
The feed material for the SPI Facility could contain lumps of plutonium having a mass up to $200 \mathrm{~g}$. The effects of a $200-\mathrm{g}$ lump of ${ }^{234} \mathrm{PuO}_{2}\left(\rho=11.5 \mathrm{~g} / \mathrm{cm}^{3}\right)$ on $\mathrm{k}$ of the drying region are presented in Cases 30 and 31 .

(alculations indicated that $k$ is sensitive to the tem. perature of the region. Cases $32-36$ summarize the varıation of $k$ with the temperature of the drying region.

The last five entries in Table VIII. Cases 37.41, are the results of calculations on the off-gas collection hupper (Case 37). the tundish (Case 38). and the secondary combustion chamber. slag tap. and holding tank (Cases 3441 ).

\section{G. Discussion of Incinerator Results}

Figure 2 shous the varation of $k$ with ${ }^{219} \mathrm{Pu}$ concen tratuon in the drying region of the incinerator. The drying reguon has a critical ${ }^{214} \mathrm{Pu}$ concentration of $3.0 \times 10^{3} \mathrm{wt}$ fraction. This is equiralent to a mass of $9.3 \mathrm{~kg}{ }^{23{ }^{234}} \mathrm{Pu}$. When the plutonium concentration decreases by a factor of $2 . k$ of the system drops to 0.74 . A nother decrease by a factor of 2 in the plutonium concentration decreases $k$ (1) 0.44 .

Because the drying regior has the lowest critical :" $\mathrm{Pu}$ mass. this region was used to study matrix effects. The SPI Facility will be processing stored wastes that are contaminated mainly with weapons grade plutonum. Consequently. a calculation was made to determine the effect of $6 \%$ : $2 \mathrm{Pu}$. The result of this calculation is shou $\mathrm{n}$ in Fig. 2. detalling the variation of $k$ in the $d_{1}$ ying region with plutonium concentration. This calculation assumed a critucal concentration of plutonium, $3.0 \times 10^{3} \mathrm{wr}$ fraction. Weapons grade plutonium lowers $k$ of the drying region by abo.t $3 \%$. Plutonium 240 has a fission threshold of about $1 \mathrm{MeV}$ : thermal neutrons can fission

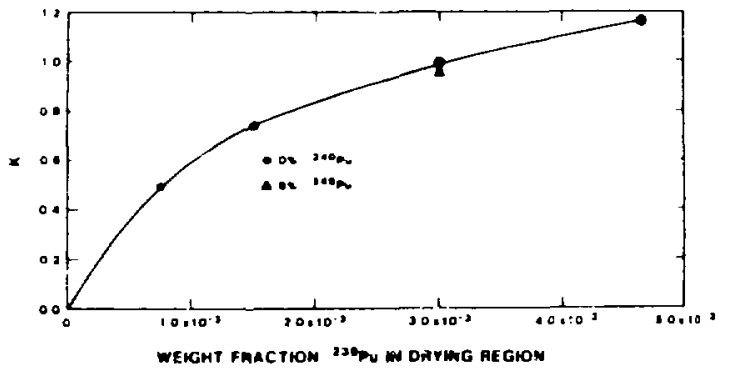

Fig. 2.

$V$ ariation of $k$ for the drying region with the weight fraction of

$\therefore \mathrm{Pu}$ in the drying region. $\bullet={ }^{179} \mathrm{Pu}: \Delta=94 \%{ }^{219} \mathrm{Pu}, 6 \%_{0}$

:" $\mathrm{Pu}$. The size of the data poinis includes the $2 \%$ std dev on the calculations. The curve merely serves to guide the eye.
${ }^{2}{ }^{4} \mathrm{Pu}$. The drying region is $5 \mathrm{wt} \%$ hydrogen or $45 \%$ atom fraction hydrogen. Thus the drying region is heavily moderated. and the neutrons rapidly lose energy. Neutrons are not able to fision ${ }^{240} \mathbf{P u}$ and there is less ${ }^{2} \mathrm{Pu}$ in the regior. Consequently. $k$ of the region decreases.

Another matrix study increased the amount of water in the drying region. One class of stored wastes is sludge drums containing a large amount of wa:er. The effect of additional water on $k$ of the drying region needed to be quantified. The drying region is nomally $25 \mathrm{wt} \%$ water. The amount of water in the drying region was arbitrarily increased by $50 \%$ to a total value of $37.5 \mathrm{wt} \%$. The $k$ of the drying region under this situation is 0.98 . The increase in water did not substantially change $k$ of the region. (Thic difference is within the standard deviatton on the MCNP calculations.) The initial hydrogen densits in the diying region thermalizes most of the fast fission neutrons. Adding hydrogen does noi produce any sut stantial additional thermalization.

The effect of adding neutron absorbers on $k$ of ih: drying region was another matrix study. Varying

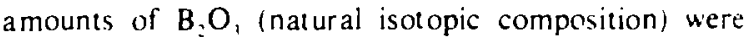
added to the material in the drying region. For this series of calculations. the "10 $\mathrm{Pu}$ concentration in the iring region was held fixed at the critical concentration. 3.0 $x 10^{\prime}$ wi fraction. Figure 3 summarizes the effect it adding $B, O$, to the material in the drying region. $A 1.0$ $x 10^{\prime}$ wi fraction of $\mathrm{B}_{2} \mathrm{O}$, reouces $\mathrm{k}$ from 0.99 to 0.9 A $1.0 \times 10^{2}=$ H. fraction of $\mathrm{B}_{2} \mathrm{O}_{1}$ reduces $\mathrm{k}$ to 0.24 . A small amount of natural boron added to the feed material appears to be a very effective technique for controlling the crivicality of the SPI Facility. When a $1.0 \times 10^{2}$ w.

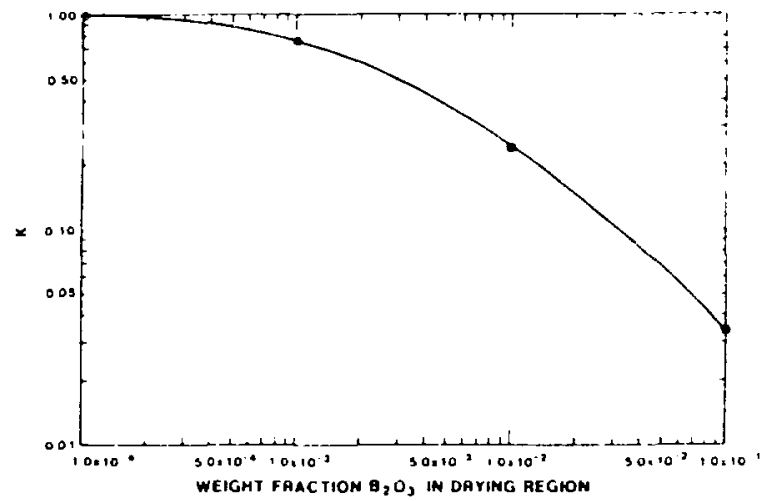

Fig. 3.

Effect of adding $B, O$, to the drying region on $k$ of the drying region. The size of the data points includes the $2^{20}$, std dev on the calculations. The curve merely serves to guide the eye. 
fractum of $\mathrm{B}, \mathrm{O}_{3}$ is in the feed mixture. the reutron spestrum that would be incident on a detector is wmeluhat harder. and there are about $15 \%$ fewer neutrons emerging from the drying region. For heavily moderated 'He tubes. the boron will probabiy cause about a $15 \%$ shange in the expected signal.

The feed material for the drying region could $\mathrm{cr}$ tals lumps of plutonium. The maximum permissible loading (f) plutomium in a 208 ( $(55$ gal.) drum is $200 \mathrm{~g}$. A cratually concervative approach for these studies con udied a 200 g spherical lump of $:{ }^{40} \mathrm{PuO}_{3}$ with the theoretcal density of $11.5 \mathrm{~g} / \mathrm{cm}^{3}$. Such a sphere of "PuO, has a radius of $1.61 \mathrm{~cm}$. The size of this sphere is ser: small compared to the volume of the drying regun of the SPI Facility. For MCNP to adequate !s simple this small volume of ":PuO, special im protancic rampling techniques were used. Two calcu lituris sere perfurmed on the lump of ${ }^{19} \mathrm{PuO}_{2}$. One Liklikaton assumed the lump was in the drying region: the resun had a critical "3" $\mathrm{Pu}$ concentration of 3.0 (1) ' ut tratuon. Without the lump. $k$ of the region is (1.)y: with the 2(x) g lump of : ${ }^{24} \mathrm{PuO}_{2} k$ of the region is 1).48. No ellect outside the $2 \%$ std dev on the calcu. batums was observed. The other calculation on the $200 \cdot \mathrm{g}$ lump of : "PuO, assumed there was no other ${ }^{24} \mathrm{Pu}$ in the iryng regon. This situation has $k=0.21$. Additional cricialats calculations must be performed if lumps of plutomum hawng a mass larger than $200 \mathrm{~g}$ are to be sliused in the feed material.

I he use of an external neutron absorber to control the crlluallt was studied by replacing the water in the water facket surrounding the drying region with natural boron. A critucal " $\mathrm{Pu}$ concentration of $3.0 \times 10^{3}$ wi fraction was in the region. L'sing external means to control criticality is sery ineffective. The boron reduced $k$ of the ystem from 0.49 to 0.46 . not a statistically significant change

The ellect external neutron jetectors would have on the neutronics of the SPI Facility was studied also. The assumpuon was made that thermal neutron deteciors would be used to monitor criticality. Thus there would be slabs of polyuhylene or other efficient neutron mod eraturs surrounding the incinerator. These external moderators were modeled by increasing the density of the water in the water jackets. No attempt was made to take into aciount that neutrons would be absorbed in the detecturs. This is a conservative approach. Increasing the density of water in the water jacket surrounding the drying region changed $\mathrm{k}$ for this region from 0.99 to 1.01. This change is not statistically significant.

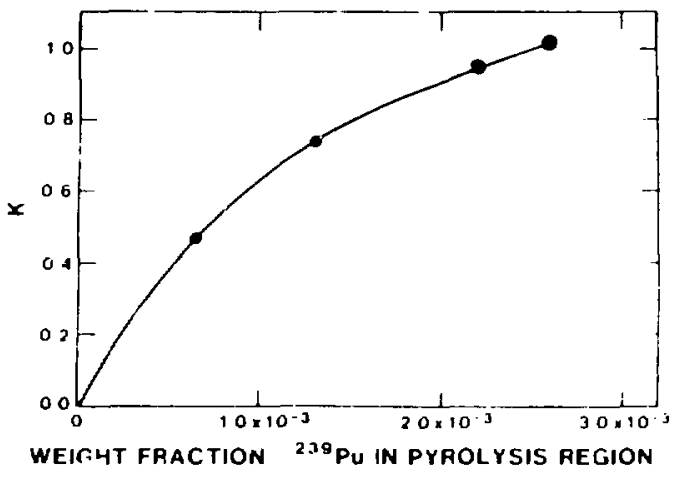

Fig. 4.

Variation of $k$ for the pyrolysis region with the weight fraction of " $\mathrm{Pu}$ in the pyrolysis region. The size of the date points includes the $2^{\text {th }}$ std dev on the calculations. The curve merely serves to guide the eye.

The variation of $\mathrm{k}$ with ${ }^{: 4} \mathrm{Pu}$ concentration in the pyrolysis region is shown in Fig. 4. The pyrolysis regro. has a critcal :"4 $\mathrm{Pu}$ concentration of $2.6 \times 10^{\prime}$ wit fraction. This is equivalent to a mass of $28.7 \mathrm{~kg}{ }^{234} \mathrm{Pu}$. A decrease by a factor of 2 in the ${ }^{234} \mathrm{Pu}$ concentration reduces $k$ to 0.74 . Another decrease by a factor of 2 in the : ${ }^{\prime 4} \mathrm{Pu}$ concentration further reduces $k$ to 0.47 . This is the same relative behavior as observed in the drvirg region.

A conservative approximation was made of the effect of plutonium build up on the inside surfaces of the drying and pyrolysis regions on $k$ of the system This is an abnormal operating condition. The layer of plutoniun was " $P$ uO, (theoreacai density $\rho=11.5 \mathrm{~g} . \mathrm{cm}^{3}$ ). Any actual layer of ${ }^{34} \mathrm{PuO}$, on the inside surfaces would probably have a density closer to $2.0 \mathrm{~g} / \mathrm{cm}^{3}$. The plating of plutonium on the inside surfaces of the incinerator does not create a criticality hazard per se. Our calcu. lations indicate that a large mass of plutonium $110 \% \mathrm{~s}$ of $\mathrm{kg}$ ) plated on the inside surfaces is required to crtate a significant criticality hazard. Build ups of this magnitude would be detected by the neutron detectors suriounding the incinerator long before any hazard develops. The real criticality hazard is the potential of this layer of plutonium breaking up and falling down into the incinerator. Nine kilograms of plutonium uniformly disuributed in the drying region is critical. Using the neutron detectors discussed below. $9 \mathrm{~kg}$ can be detected on the walls of the incinerator. Assuming a safe operating condition of $k \cong 0.20$. $800 \mathrm{~g}$ can be plated on the walls. and a criticality hazard will not develop if that quantity falls into the incinerator, even if all the material coalesces into one lump. 


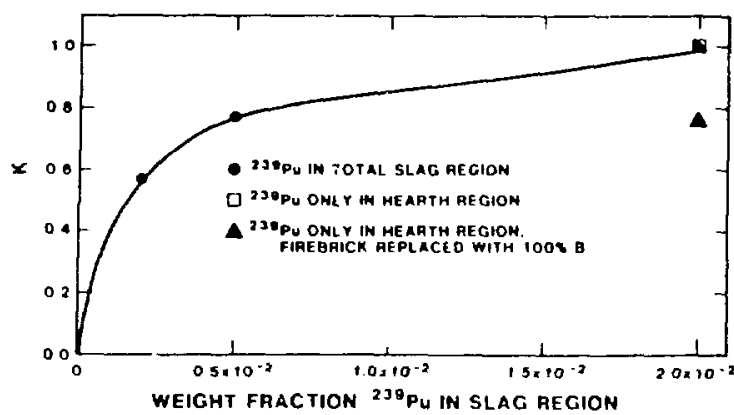

Fig. 5.

Dependence of $k$ on the weight fraction of ${ }^{2 T} \mathrm{Pu}$ in the slag region. The size of the data foints includes the $2 \%$; std dev on the calculations. The curve merely serves to guide the eye. $\bullet=$ . ${ }^{14} \mathrm{Pu}$ in the total slag region. For the critical concentration 2.0 * $10:$ wr fraction, $\mathrm{k}$ was calculated for ${ }^{210} \mathrm{Pu}$ on!y in the hearth region ([7) and for " $\mathrm{Pu}$ orily in the hearth region with the firebrick surrounding the hearth replaced with $100 \%$ natural boron (A).

Figure 5 shows the variation of $\mathrm{k}$ with ${ }^{29} \mathrm{Pu}$ concentration in the slag region. The slag region has a critical ${ }^{20} \mathrm{Pu}$ concentration of $2.0 \times 10^{-2}$ wt fraction. This is equivalent to a mass of $271 \mathrm{~kg}{ }^{234} \mathrm{Pu}$. For the slag region. a decrease by a factor of 4 in the ${ }^{234} \mathrm{Pu}$ concentratio. reduces $k$ to 0.77 . A further decrease by a factor of 2.5 in the ${ }^{\text {" }} \mathrm{Pu}$ concentration reduces $\mathrm{k}$ to 0.57 . Thus the slag region is not as sensitive to changes in ${ }^{239} \mathrm{Pu}$ concentration as are the drying and pyrolysis regions. However, it is expected that the $1.0 \times 10^{-2}$ wt fraction of $\mathrm{B}_{2} \mathrm{O}_{3}$ placed in the slag region will make a similar reduction in $k$ as it did in the drying region. For these calculations of $k$. total blockage to the level of the burners was assumed. The critical mass of the slag region is so large mainly because of the slag tap and holding tank. Blueprints $\alpha$ ! the slag tap and holding tank had a dimension labeled "as required," which was assumed to be $85 \mathrm{~cm}$.

Several studies for the slag region were made because sampling problems were observed when the entire region was treated as a whole. Subsequent calculations were made only on the hearth region and only on the slag tap and holding tank area. (See Fig. ) for a definition of these regions.) Figure 5 compares the results for the hearth region with those for the total slag region. The comparison is for a single ${ }^{234} \mathrm{Pu}$ concentration, $2.0 \times 10^{-2}$ $w t$ fraction. This weight fraction is critical for the total slag region, and there is no difference in $\mathbf{k}$ for the hearth region and the total slag region. The hearth region has a critical mass of about $80 \mathrm{~kg}{ }^{234} \mathrm{Pu}$. When the firebrick is



Fig. 6.

Dependence of $\mathrm{k}$ on the weight fraction of $:{ }^{14} \mathrm{Pu}$ in the slag region. The size of the data points includes the $2^{4} 4$ std dev on the calculations. The curve merely serves to guide the eye. - = :" $\mathrm{Pu}$ in the total slag region. Additional calculations were made for the critical concentration $2.0 \times 10^{\prime}$ wr fraction. The - gives $k$ for : ${ }^{14} \mathrm{Pu}$ only in the slag tap. The $\Delta$ gives $k$ when there is only ${ }^{\text {in }} \mathrm{Pu}$ in the slag tap. and the density of water in the water jaciket surrounding the slag tap has been increased by a factor of 5 . The $a$ gives $k$ for ${ }^{14} \mathrm{Pu}$ only in the slag tup when the density of the firebrick surrounding the slag tap has been increased by a fuctor of 10 .

replaced totally with natural boron, $k$ of the hearth $\therefore$ an drops significandy to 0.76 .

The comparison between the total slag region and the slag tap and holding tank only is shown in Fig. 6 . When a $2.0 \times 10^{2}$ wt fraction of ${ }^{234} \mathrm{Pu}$ is present only in the slag tap and holding tank. $\mathrm{k}$ of the incinerator is 0.86 . For this same concentration in the total siag region. $k=0.99$. Thus $k$ of the total siag region is effectively $k$ of the hearth region which is the most reactive region. To a certain extent, the hearth region is neutronically isolated from the slag tap adi' holding tank. This is partially due to a feature of the calculational model. The blueprints of the slag tap region had a dimension "as required." As this dimension is increased, the two regions of the slag become more isolated.

The $k$ of the slag tap and holding tank is lower because of the absence of adequate neutron moderators surrounding the slag tap and holding tank. They are surrounded by only 5.08-cm-(2-in.-) thick firebrick and a 2.54-cm-(1-in.-) water jacket. When the density of the water in the water jacket surrounding the slag tap and holding tank is artificially increased fivefold, $\mathrm{k}$ increases to 0.96 . This effect increases the neutron noderation near the surface of the slag tap and holding tank and increases the number of fissions near the surface. Artificially increasing the density of the water also simulates the effect of a thermal neutron detector. 
heavily moderated with water or polyethylene, used to monitor activity in the slag tap and holding tank region.

The effect of external neutron moderators was established also by artificially increasing the density of the firebrick surrounding the slag tap and holding tank. A tenfold increase in the firehrick density increases $k$ to 1.04. The effect of external moderators around the slag tap and holding tank is so noticeable because the slag does not have any efficient neutron moderators in it. The interior of the slag tap and holding tank appears to be an infinite medium, but the outer few centimeters of the slag tap and holding tank are easily infuenced by external moderators.

After the critical ${ }^{2: 4} \mathrm{Pu}$ concentration of each region was determined, a calculation was made on the entire incinerator with each region having a critical concentration of ${ }^{14} \mathrm{Pu}$ in it. The $k$ of the entire system was 0.99 . Within the $2 \%$ std dev on the calculations. there is no difference between calculating $k$ for each region separately and calculating $k$ for the entire incinerator. There is litte neutron transfer between the different regions. Neutronically, each region appears to be independent. We are thus justified in treating each region separately.

Figure 7 summarizes the temperature effect on the incinerator, specifically the drying region. The drying region has an operating temperature of $1000^{\circ} \mathrm{C}$. For the calculations summarized here, the temperature of this region was varied from 500 to $1500^{\circ} \mathrm{C}$. The temperatures of all other regions were held fixed at the values listed in Table VIl. For all temperature calculations, the d:ying region had a ${ }^{234} \mathrm{Pu}$ concentration of $3.0 \times 10^{3} \mathrm{wt}$ fraction, a critical concentration when the temperature is $1000^{\circ} \mathrm{C}$. The $\mathrm{k}$ of the drying region va ies from a low of $0.38 \pm 0.02$ for $\mathrm{T}=500^{\circ} \mathrm{C}$ to a high of

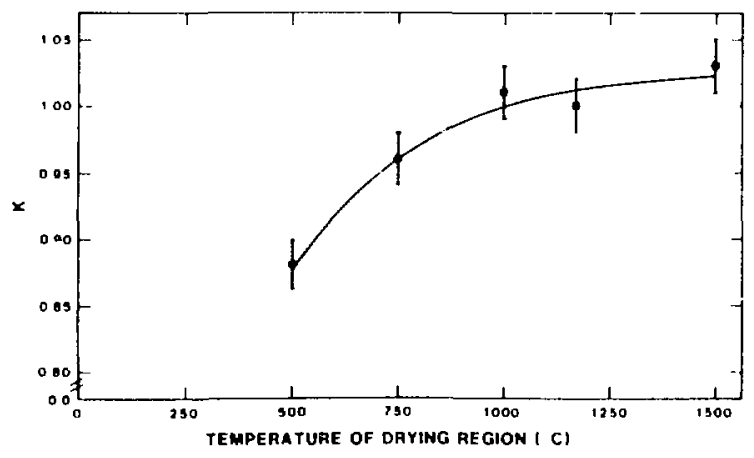

Fig. 7.

Variation of $k$ with the temperature of the drying region, which contained a $3.0 \times 10^{1}$ wi fraction of ${ }^{299} \mathrm{Pu}$. The curve merely serves to guide the eye.
$1.03+0.02$ for $\mathrm{T}=1500^{\circ} \mathrm{C}$. There is a no:iceable rise in $k$ as the temperature rises from 500 to $1000^{\circ} \mathrm{C}$. For temperatures above $1000^{\circ} \mathrm{C} . \mathrm{k}$ is much less sensitive to changes in temperature. As the temperature rises from $1000101500^{\circ} \mathrm{C}$. I varies within the $2 \%$ std dev on the calculations. Because the drying region operates at $1000^{\circ} \mathrm{C}$. any increase in temperaturc should produce only small fluctuations in $k$. Any decrease in operating temperature from $1000^{\circ} \mathrm{C}$ decreases $k$. These calculations emphasize the need to use correct temperatures for the different regions of the incinerator and for the cross section evaluation because of the considerable Doppler broadening effects on neutron resunances.

\section{H. Secondary Combustion Chamber, Slag Tap, and Holding Tank}

The calculational model of the secondary coml-ustion: chamber. slag tap. and holding tank ${ }^{*}$ is shown in lig. 8 . The secondary combustion chamber, slag tap. anc. holding tank has cylindrical symmetry. The lower regio' is surrounded by a $5.08 \cdot \mathrm{cm}^{-}{ }^{2}$.in.-) thick firebrick, which is surrounded by a $2.54 \mathrm{~cm}-(1$-in.-) thick water jact $-t$ The compositions of the slag material and tie firebrick were presented in Tables ill and IV, respectively. Figure 9 shows the placement of materials in the secondary combustion chamber. From Table VIII, the calculated critical " tion chamber, slag tap. and holding tank is between $4.0 \times 10^{2}$ and $5.0 \times 10^{2}$. This is equivalent to a mass between 450 and $560 \mathrm{~kg}{ }^{234} \mathrm{Pu}$. This ${ }^{234} \mathrm{Pu}$ weight fraction is to be compared with a $2.0 \times 10^{2}$ critical wt fraction of ${ }^{204} \mathrm{Pu}$ in the slag region. The secondary combustion chamber. slag tap. and holding tank unit does not have as much moderatıng material around it as does the slag (hearth) region. Consequently, the critical concentration of ${ }^{274} \mathrm{Pu}$ in the secondary combustion chamber. slag tap, and holding tank is greater than that in the slag region.

\section{Tundish}

The tundish ${ }^{4}$ is a parallelepiped with dimensions $426.72 \mathrm{~cm}$ (168 in.) $\times 365.76 \mathrm{~cm}$ (144 in.) $\times 213.36 \mathrm{~cm}$ (84 in.) high. The bottom and sides are surrounded by a $60.96-\mathrm{cm}-\left(24-\mathrm{in}_{\text {.- }}\right)$ thick firebrick. Surrounding the firebrick is a $5.08-\mathrm{cm} \cdot(2-\mathrm{in.})$ thick type 316 stainless steel 


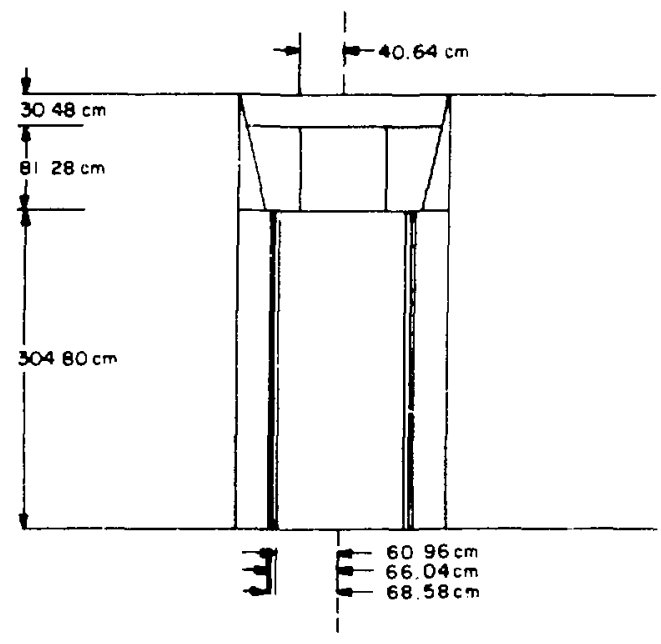

Fig. 8.

Calculational geometry of the secondary combustion chamber, slag tap, and holding tank. Apprepriate dimensions of important regions are given.

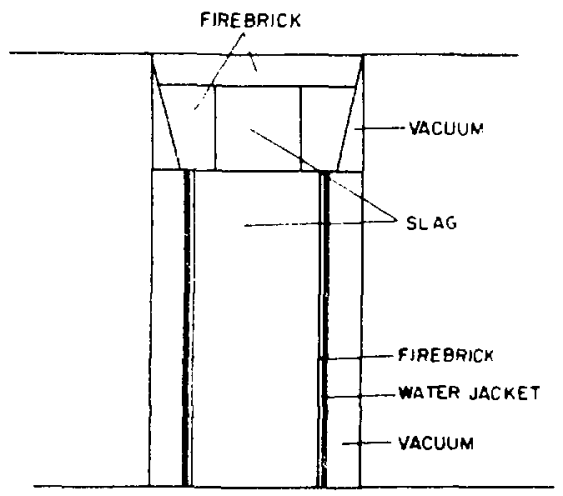

Fig. 9.

Material regions in the secondary combustion chamber, slag tap, and holding tank.

jacket. The material in the tundish is identical to that in the slag region of the incinerator, which was presented in Table III. Initiaily, the tundish would be expected to behave neutronically similar to the slag region and the secondary combustion chamber, slag tap, and holding tank. However, the critical ${ }^{239} \mathrm{Pu}$ concentration in the tundish is an order of magnitude less (see Table VIII). The critical wt fraction in the tundish is $4.0 \times 10^{-3}$. This is equivalent to $370 \mathrm{~kg}{ }^{239} \mathrm{Pu}$. The slag does not have any efficient neutron moderators in it. The interior of the tundish appears infinite to the neutrons and thus is not affected by surrounding material. This is not true of the slag material near the outside edges of the tundish. The tundish is surrounded on five sides by firebrick and has more moderating material around it than does the slag region of the incinerator or the secondary combustion chamber. The firebrick surrounding the tundish is thick enough to moderate and reflect neutrons into the tundish. These reflected neutrons are of the right energy to fission the ${ }^{2.14} \mathrm{Pu}$ near the edges of the tundish, enhancing the fission rate and lowering the critical ${ }^{39} \mathrm{Pu}$ concentration.

\section{J. Off-Gas Collection Hopper}

The off-gas collection hopper is a $152.40-\mathrm{cm}-(60$-in.-) dism, 182.88-cm-(72-in.-) high cylinder. The walls of the collection hopper are $0.48-\mathrm{cm} \cdot(0.19$-in.-) thick type 316 stainless steel. The composition of material in the collection hopper was presented in Table VI. The critical mass of ${ }^{34} \mathrm{Pu}$ in the collection hopper is calculated to be $50 \%$ by weight (see Table VIII). This is equivalent to a ${ }^{23.4} \mathrm{Pu}$ mass of $2140 \mathrm{~kg}$, which initially seemed too large a mass. However, the material in the collection hopper does not contain any neutron moderators, and the collection hopper is not sur:ounded by neutron moderators. Several secondary calculations were made. artificially adding hydrogen to the composition. As the amount of hydrogen was increased. the critical mass of ${ }^{239} \mathrm{Pu}$ decreased. When the amount of hydrogen approached that in the drying of pyrolysis regions, a plutonium concentration similar to that in the drying or pyrolysis regions was calculated.

\section{K. Conciusions from Monte Carlo Studies}

If only properly screened input material is processed, there does not appear to be a serious criticality hazard for the SPI Facility. The region having the largest criticality hazardi is the drying region, where the critical mass of ${ }^{2.39} \mathrm{Pu}$ is $9.3 \mathrm{~kg}$. The next most hazardous critical regior. would be the pyrolysis region, which has a critical mass of about $30 \mathrm{~kg}{ }^{239} \mathrm{Pu}$. All other regions of the incinerator and secondary structures have critical masses greater than $200 \mathrm{~kg}{ }^{239} \mathrm{Pu}$. Forty-five 208- $\ell$ (55-gal.) drums, each containing $200 \mathrm{~g}$ of plutonium. could be put into the $S$ PI Facility at one time before causing a critical situation. This assumes that no build-up occurs.

The average plutonium concentsation expected in the SPI Facility is $1 \mathrm{~g}$ piutonium per $50 \mathrm{~kg}$ waste. This is a wt 
fraction of $2.0 \times 10 \because$ There is no criticality problem in any region of the SPI Facility for this average waste. The drying region, which has the lowest critical mass. has a critical weight fraction that is one hundred times larger than that of the average waste. Other regions of the SPI Facility have critical weight fractions two to three orders of magnitude greater than that of the average waste.

However, one simple operation would greatly reduce any conceivable criticality hazard. A small amount of $\mathrm{B}_{2} \mathrm{O}_{3}\left(1.0 \times 10^{2} \mathrm{wt}\right.$ fraction) added to the feed mixture in the drying region reduces $k$ from 0.99 to 0.24 .

The addition of water to the feed material of the incinerator does not produce any statistically significant change in $k$ of the drying region. Thermal neutron counters are expected to have minimal effects on the neutronics of the incinerator. Likewise, the use of external nelutror absorbers to control $\mathrm{k}$ of the incinerator is not an effect ve technique. Such a technique has about a $20 \%$ maximum effeci on $\mathrm{k}$. To get this effect. either the water in the water jacket or the firebrick must be replaced tutally with boron. Such changes are not possible because the water is needed for its cooling action. and the firebrick is needed for its thermal-insulating properties.

Lump:i of plutoniunn. taken as $20 \mathrm{~g}$ or less of ${ }^{234} \mathrm{PuO}_{2}$, will not pose a criticality problem. It takes a large amount of plutonium build-up on the inside surfa.es of the drying and pyrolysis regions to create a criticality hazard. However, the real criticality hazard with plutonium build-up develops if the layer of pluernium falls off the wall into the incinerator. Any in build-up can be monitored br detectors sur-

'y the SDI Facility and alarm sounded long belore any hazard develops.

The incinerator itself. excluding the tundish: secon dary combustion chamber. slag tap, and holding tank: and of -gas collection hupper, has a positive temperature coefficient. An increase in the temperature of a region increases $k$ of the region. This increase in $k$ is most noticeable as the temperature in the drying region increases from 500 to $1000^{\circ} \mathrm{C}$. Above $1000^{\circ} \mathrm{C}$, k appears to level off with increasing temperature. The temperatures of the plutonium containing regions are between 1000 and $1500^{\circ} \mathrm{C}$. Thus changes in temperature should not produce large changes in $\mathrm{k}$. For the drying region. an increase from 1000 to $1500^{\circ} \mathrm{C}$ changes $\mathrm{k}$ by at most $2 \%$.

\section{DIRECT CRITICALITY MONITORING}

\section{A. Section Summary}

We define direct criticality monitoring as the measure. ment of radiation directly associated with the fissile material producing the criticality hazard. This is distinguished from indirect criticality monitoring, which uses the differences between input and output assays to infer residual fissile mass in the facility.

We examined both passive and active techniques for direct monitoring of system criticality, inclucing total count rate, Feynman Variance, and Rossi-alpha. We identified, based on the very soft neutron spectrum emerging from the drying and pyrolysis regions, a particularly appropriate neutron detector design that can be used for both passive and active measurements. We calculated responses for these detection systems for efficiencies typical of the SPI Facility criticality monitoring geometry and demonstrated with measurements on several plutonium multiplying systems the feasibility of this lype of monitoring system. If the criticality hazard is judged to be sufficiently serious in other regions of the SPI Facility. a similar neutron monitoring system can be easily installed and operated in those regions.

A passive neutron system should be adequate for direct criticality monitoring. The passive neutron data would be analyzed using both the total neutron count rate and a time-correlated analysis. The former provides a sensitive, very timely monitor of the system. A time-correlated analysis is used to minimize the interference from neutrons from matrix generated $(\alpha, n)$ reactions. An upper limit alarm level can be set using the total count rate while the time-correlated analysis is used to determine, with a longer time constant, the actual system multiplication.

A compact pulsed neutron generator can be incorporated into the system. This feature allows roth the system multiplication and the fissile material build-up to be determined. It is clearly a more complicated system than the passive system.

\section{B. Passive Neutron System}

The MCNP calculations of the SPI Facility in Sec. I included neutron spectral output in the regions external to the drying and pyrolysis regions. These calculations 
indicate a very soft neutron spectrum produced prinari. ly by interactions with hydrogen within these regions and in the water jacket surrounding them. Depending on the location. $1 / 3$ to 12 of all nestrust in the potential detector region are near thermal encrgies. For this situation. an appropriate neutron kcketor is shown in Fig. 10. This design onsibs af an “. spen faced sandwich" of "He proportional culunter and polyethylene. The bare porion of the 'He propultienal counters faces the source and has a calculated efficielace "of about $95 \%$ for incident thermalized nestrom. Ihe efficiency falls off rapidly with energy: the enceres at: ated efticiency for

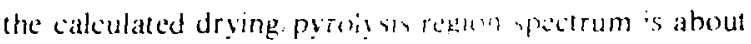
4() .5()$\%$.

Because the neutron conent ritie in proportional to detector solid angle. the latgest promble solid angle should be intersepted in the arth!? phrolysis regions. A

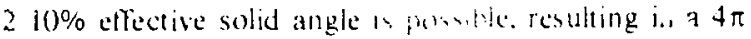
detection efficiency in the range if 1 5.

The total passive neutron coum ritie cian be used as a criticality monitor. Historicall!.". jus uch a system was used to monitor the state of the sysem criticality in fast critical assembly research and development work. The typical SPI Facility waste matrix colld produce

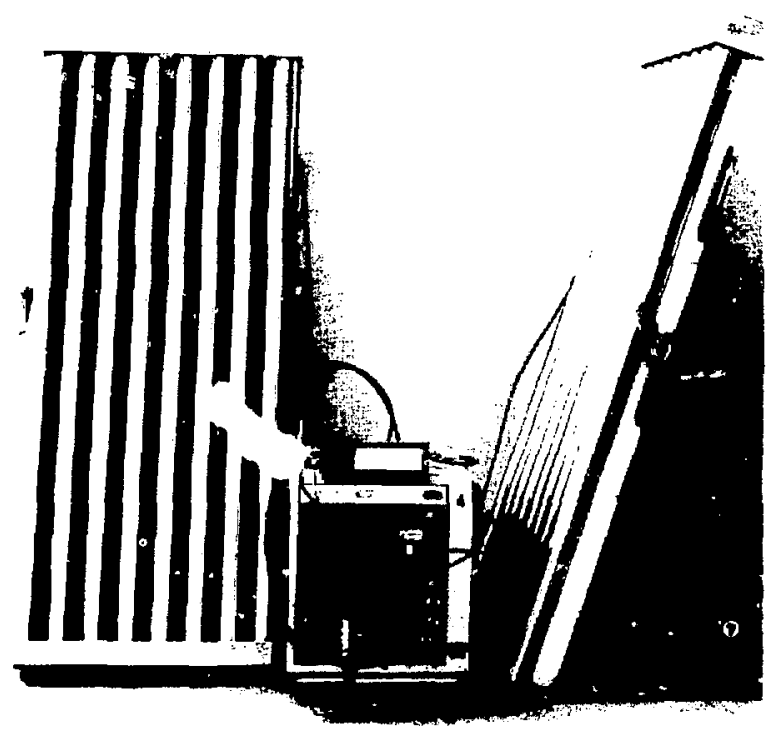

1-ig. 10

Typical set of 'He/polyethylene open fuced sanduich neutron detectors. This configuration is optiniced fir a highly mod erated incident neutron spectrum. $(\alpha, n)$ reactions. If a paricular load of waste were to contain significant amounts of, for example. Be. B. or F (a very credible possibility ${ }^{10}$ ), then any TRL present can induce $(a, n)$ reactions. Table IX (from Ref. 11 ) gives the measured neutron yields for typical TRU alpha particles incident on various materials with low atomic numbers.

A batch of waste containing modest amounts of plutonium combined with significant amounts of Be. B. or $F$ could give a total neutron count rate that would appear to signal the presence of a significant. -iticality hazard. This would constitute a false aiai. 'or a monitoring system based solely on the total tleutron count rate

Because the very nature of system multiplication guarantees a large number of time correlated neutrons. one solution to the false aiarm problem produced by $(a, n)$ neutrons is time-correlation measurements. Many techniques have been devised to accomplish this. ${ }^{12.12}$ Of particular applicability. however. is the Feymman or Reduced Variance technique. ${ }^{1 s .1 *}$ This techniçue has been developed at LASI in connection with a Nuclear Emergency Search Team (NEST) requirement tor portable system multiplication measurement equipment. A prototype module of such a system is shown in Fig. 11.

From an arialysis of the basic physics of a multiplying system, one can show that ${ }^{14}$

$$
Y=\text { const. } \frac{M^{-} \cdot\left(M^{-}-1\right)}{-2^{--}} \text {, }
$$

TABLE IX THICK TAKGET NEUTRON YIELDS
FOR 5.3.MEV ALPHA PARTICLES

\begin{tabular}{cc} 
Target Material & Observed Neutron Yieid $/ 10^{\mathrm{h}}$ a \\
\hline $\mathrm{Li}$ & 2.60 \\
$\mathrm{O}_{2}$ & 0.07 \\
$\mathrm{Na}$ & 1.50 \\
$\mathrm{Mg}$ & 1.40 \\
$\mathrm{Al}$ & 0.74 \\
$\mathrm{Si}$ & 0.16 \\
$\mathrm{C}$ & 0.11 \\
$\mathrm{~F}_{2}$ & 12.00 \\
$\mathrm{~B}$ & 24.00 \\
$\mathrm{Be}$ & 80.00
\end{tabular}

Ref. 11. 


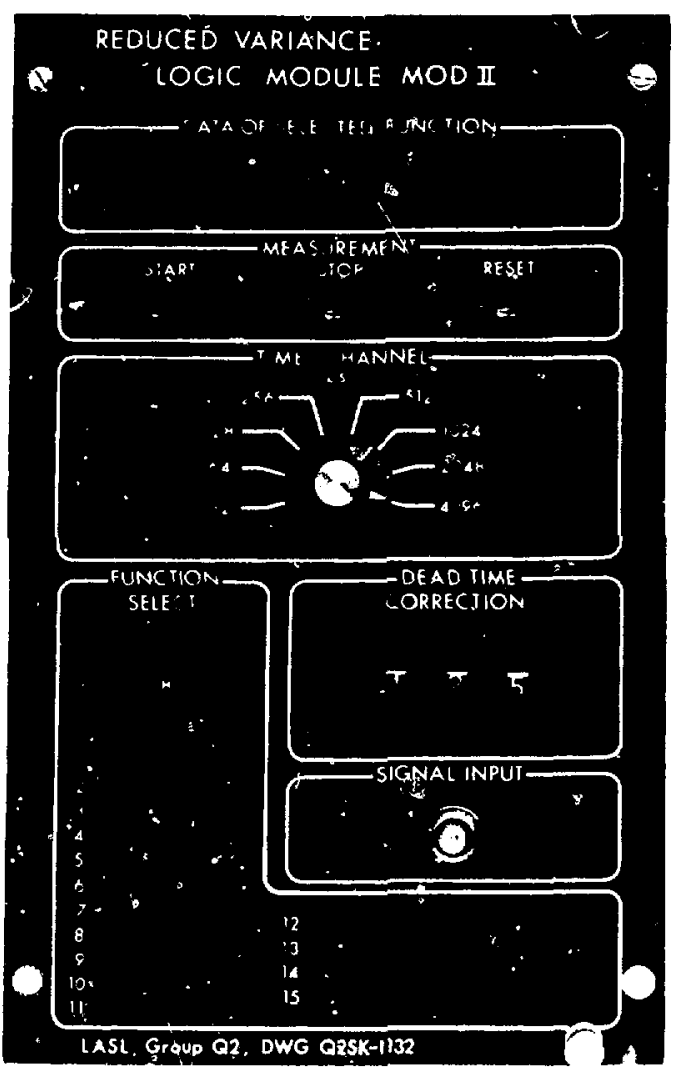

Iiv 11.

Front panel sieu of microprocesser based leymen b ariance data collection/anaibsia module.

where $M$ is the system multiplication. $\bar{v}$ is the average number of prompt neutrons emitted in a neutron induced fission of the fissile material. and $Y$ is a quantity generally defined as the "variance ()-nean ratio."

Experimentally:

$Y=\frac{\overline{C^{2}}-\bar{c}^{2}}{\bar{C}}+\frac{2 \bar{c}}{T}-1$,

where $\bar{C}$ is the experimentally measured average ccunts-per random gate. $T$ is the length of the randomly generated gates, $\bar{C}^{2}$ is the second moment of the observed distribution. and $\tau$ is a system deadtime. The system deadtime is measured experimentally by placing a time-uncorrelated source. such as an $(\alpha, n)$ source, near the detection system. For this source, $Y=0$ and $t$ may be obtained.

In the experimental situation of a mixed $(a, n)$ and fission source, the following quantity is useful.

$Q=\overline{c^{2}}-\bar{c}^{2}-\bar{c}+\frac{2 \bar{c}^{2} z}{T}$.

A comprehensive study (theoretical and experimental) of the general problem of mixed $(\alpha, n)$, spontaneous fission and system multiplication has been completed, and an initial report is being prepared. ${ }^{\text {it }}$

As a demonstration of the effectiveness of the Feyn. man Variance technique to determine system mult. plication, we completed a series of measurements on some plutonium samples ranging in mass from about 0.5 to $4.0 \mathrm{~kg}$. The cylindrical counting geometry was similar to that expected for an implemented neutron detection system in the SPI Facility around either the pyrolysis or drying regions. However, no attempt was made to mock up matrix effects for these measurements. That level of effort was beyond the scope of this study. These measurements serve to demonstrate the feasibility of the technique for piutoniuli masses of a size (as indicated by our MCNP calculations) that could be expected to result in signiñcant system multiplication. This method is used routinely in the LASL NEST effort.

Figure 12 shows a plot of the basic experimental data with the quantity $1+Y$ plotted as a function of plutonium mass. This results in a scatter plot with a



Fig. 12.

Feynman Variance data $(I+Y)$ obtained for a set of multiphying plutonium samples and plotted as a function of plutonium mass. Detection system used cylindrical geometry. 
generally increasing trend as a function of increasing plutonium mass. The reason for the large scatter is that plutonium mass alone is not a good indicator of system multiplication. Some of these samples were spherical, some were cylindrical. and the sample density and ${ }^{240} \mathrm{Pu}$ isotopic content varied greatly.

When the same data are plotted differently (see Fig. 13), a very smooth curve results. Here $1+Y$ is plotted as a function of the quantity $\mathrm{Q} \div{ }^{i+1} \mathrm{Pu}$ mass. Dividing by the ${ }^{241} \mathrm{Pu}$ mass, which was known for all the samples. normalizes all samples according to the "driving source" preserti- ${ }^{241} \mathrm{Pu}$ spontaneous fission. If the samples were nonmultiplying, all would yield the same $\mathrm{I}+\mathrm{Y}$ value. The actual system multiplication for each of the samples used was not determined independently. However, a MCNP calculation of the largest sample was made and indicated $M \cong 3.0$ (or $k \cong 0.67$ ). This corresponds to the largest $1+Y$ value measured. about 1.9. Using this value to establish an approximate multiplication for the low :st $1+Y$ valuc measured leads to an estimate of $M \cong$ $1.2(k \cong 0.17)$.

In Fig. 14. we show the calculated Feynman Variance quantity $Q$ per fission as a function of system inulti plication $M$ for the anticipated range of $4 \pi$ detection efficiencies. We would estimate the technique to be sensitive to $k$ of $0.05 \cdot 0.10(\mathrm{M}=1.05-1.11)$.

To determine $1+Y$, uc generally acquire data for $10^{\mathrm{K}}$ random (but back to back) gates. The gate length must be matched to the detector/SPI Facility dieaway time Fo- the SPI Facility monituring system. we es timate that $\mathrm{T} \cong 1 \mathrm{~ms}$ is appropriate. This indicates a $1000 \mathrm{~s}$ count time is needed to acquire a typical set of data. However.

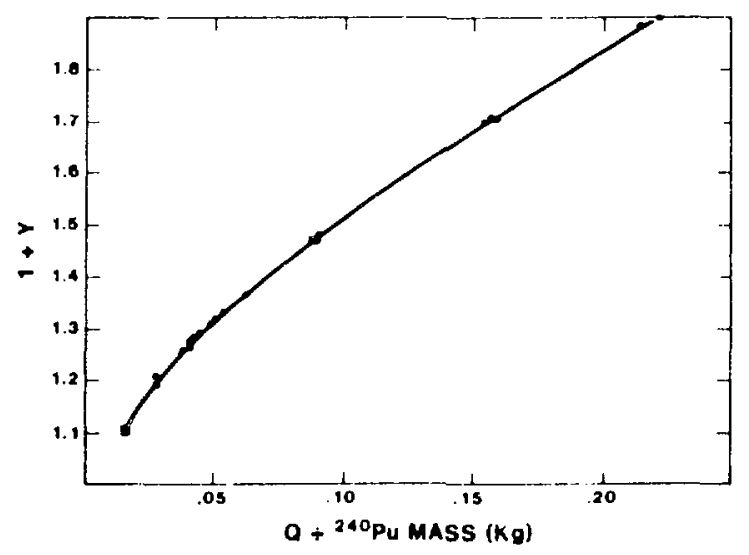

Fig. 13.

Same Feynman Variance data $(I+Y)$ as shown in Fig. 12 now plotted as a function of $Q$ divided by ${ }^{216} \mathrm{Pu}$ mass. for a fixed . stallation and use as a criticality monitor, a technique of time averaging would be appropriate. We have used this sype of analysis successfully in other field instrun.entation but not in the Feynman work. Here one could use a 1000-s analysis period. for instance, but update it more frequentiy. For example, a $1+Y$ could be calculated every 5 or $10 \mathrm{~s}$, with exclusion of the "oldest" $5 \mathrm{or} 10 \mathrm{~s}$ of data and inclusion of the "newest" 5 or $10 \mathrm{~s}$ of data. If a significant change in $1+Y$ occurs in the 5 or $10 \cdot \mathrm{s}$ period, this would be reflected in the latest $1+\mathrm{Y}$ value because a few highly correlated events (neutron chains) would be weighted very strongly in the $1+Y$ calculation. On the other hand. by ictaining a relatively long total count time, much better counting statistics are obtained. This avoids the frequent false alarm problem that is always associated with poor counting statistics.

Another approach would be to set up a combined "AND" alarm system in which both a high I + Y value and a high total count rate are required before an alarm is sounded. This AND alarm approach has been used successfully at L.ASL. One can be sure that the most severe operational problem associated with a criticality monitor (or any other monitor) will be the false alarm prot?em. It is beyond the scope of this study to recommend a more specific solution to this false alarm problen. We believe. however, that the basic sensitivity

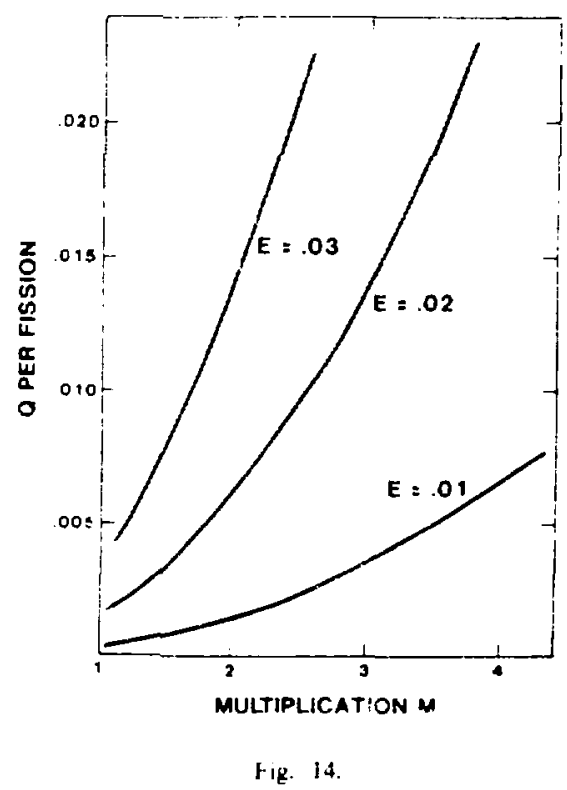

Catculated Feynman Varance quantity (Q per fission) as a function of system multiplication. The $4:$ detection efficiencies (0.01. 0.02, 0.03) are in the expected range for the SPI criticality monitoring system. 
1. well in hand with the 'He/polyethylene open-faced sandwich detectors and that some combination of total erunt rate and time-correlated (Feynman Variance) analysis will be sufficient. The analysis procedures are arailable at LASL and appropriate hardware exists. These are diccussed in the references cited above. ${ }^{1:}$ is

\section{Active Neutron System}

If the passive neutron criticality monitor cannot provide a rapid enough response time, a pulsed active ysem might be required. Pulsed neutron sources based (n) thic D. T reaction are commercially available" and bate been used for various safeguards and activation analys purposes. When the neutron correlation meth od are reduces to their essence (Rossi-alpha. Feynman Vartuncel. one finds that the puised neutron theory is uenical $w$ that used for a passive analysis. One measures barkous features of neutron multiplying chains. and it matters lutte of the initiating event occurs sponta neousls or anduced.

The Rosstalpha measurement generally involves measurng the prompt dieaway time of a multiplying ancombly The 'He polyethylene open faced sandwich neutron detectors discussed above are capable of monturing the promot dieaway time and could be used III an dithe pulsed mode. Fast recovery electronics are aritlathle (currently in use at LASL and elsewhere) for these detcutors so that they can be operated in the presence of an interrogating pulsed source. One needs to ketp apers the actse neutron option. A pulsed neutron Eescratt: of more that: adequate neutron output $\left(1 \times 10^{\text {h }}\right.$ in nulse. $\mid(x)$ pps pulse rate) is currently available. ${ }^{1-}$ This vem in quite small. It was designed to fit down small diameter horeholes for the oil well and uranium pros pectung industries. Thus, it could be installed at the SPI f acilit? around the pyrolysis or drying region without (xccupung much space. Indeed. it is only slightly larger than a ungle 'He proportional counter.

\section{DISTINGUISHING BETWEEN FISSILE AND FERTILE MATERIALS IN NUCLEAR WASTE AT ALL. ST AGES}

\section{A. Section Summary}

Fissile material is hest distinguished from fertile material hy using assay techniques that are fissile specific. In this regard. techniques based on thermal neutron induced fission provide the solution. Such techniques specifically measure " $\mathrm{U}$. "Pu. " ${ }^{2+1} \mathrm{Pu}$, and other fissile isotopes. while giving no response for the common fertile isotopes. such as ${ }^{\text {"k }} U$. Techniques based on thermal neutron fission and directed specifically to measurements in typical waste matrices ${ }^{1 / 14}$ are currenty under development. One or more of these active neutron techniques should suffice to determine the fissile material content in the variet! of wastes the SF! Facility is likely to encounter. These techniques can probably be developed (6) handle any particularly difficult matrix (such as sludges or concrete in the leadtime available before the SPI Facility is scheduled to be operational.

As an adjunct to thermal neutron interrogation tech niques. passive neutron coincidence methods can be used to quantify plutonium content in waste of reasonably well characterized plutonium isotopic content. such as is the case for the bulk of the waste scheduled for processing in the SPI Faciaty. Photofission techniques are not easily applied to the general fissile assay problem. If unknown and significant amounts of ${ }^{2} \mathrm{H}$. ${ }^{9} \mathrm{Be},{ }^{1} \mathrm{C} .{ }^{1} \mathrm{O}$. :k $U$. "T: $:$ or other isotopes that have low $(\gamma . n)$ thresholds or significant photofission yieids are mixed in the waste. photofission techniques may indicate false positive fissilo assay amounts. In some very dense matrices. homerer. photofission lechniques may be needed. The assay problem is strongly matrix dependent. Contunuing rescarch and development efforts in this field ull likely provicie adequate solutions in the next feu years.

\section{B. Active Thermal Neutron Fission Techniques}

The nuclear safeguards groups at LASL have de veloped" a "Cf neutron source. thermal neutron in duced fission technique that is currently being specialized for use with $208 /$ contaners of high density nuclear waste. The technique, known as the "2"Cf Shuffler." consists of moving a strong $\left(10^{4} \cdot 10^{10} \mathrm{n} / \mathrm{s}\right)^{292} \mathrm{Cf}$ neutron source into an interrogation cavity to induce fission reactions in any fissile material present and then remow. ing it to a storage shield during a count cycle. Highly efficient 'He neutron counters are used to count delayed neutrons from the induced fissions during this part of the cycle. In test hed measurements at LASL using a 4.6 $x 10^{k} \mathrm{n}$ s " $\mathrm{C}$ r source. a 3o-detection limit (for a 700 -s total imadiation/count period) of about $67 \mathrm{mg}$ of ${ }^{239} \mathrm{Pu}$ $w$ as determined. In scaled-up designs of this system 
using a 10-25 times stronger ${ }^{32} \mathrm{Cf}$ source and a more efficient detection system, plutonium assay detectior: limits of about $4 \mathrm{mg}$ have been projected. ${ }^{18}$ A conceptual Jesign of the " $\mathrm{Cf}$ Shuffer is shown in Fig. 15.

The LASL.F.G\&G/Santa Barbara waste assay work ers are developing techniques based, in part. on neutron irradiation using a pulsed photoneutron source. ${ }^{19} \mathrm{~A}$ pulse of photoneutrons is thermalized and us ad to irradiate a waste container around which is placed a $4 \pi$ solid angle neutron detector. Following the irradiation, delayed neutrons from the induced fission reactions are counted. In a prototype 208-f barrel-size detection system, a 36 detection limit of a feve milligrams of ${ }^{239} \mathrm{Pu}$ or ${ }^{219} \mathrm{U}$ has been obtained in a typical few 100's of seconds irradiation with photoneutrons produced by 10 to $18 \mathrm{MeV}$ bremsstrahlung.

A technique ${ }^{\prime}$ originally developed for use in the Enrichment Plant Safeguards Program at LASL is now under development for use in the Waste Management Program. This technique, called the "Differentıal Dieaway Technique (DDT)," uses pulses from a $14 \mathrm{MeV}$ neutron generator as a source of ultimately thermalized neutrons. The generator is placed within a graphite lined interrogation cavity (see Fig. 16). which is backed with polyethylene for additional neutron inoderation. re flection, and personnel shielding. External to the graphite layer. but inside the bulk polyethylene layer. are fast-dieaway moderated 'He neutron detectors. The neutronic properties of this system are shown in Fig. 17. which shous the thermalized neutron time history produced by a pulse irom the neutron generator in (a) the external neutron detector. and (b) the interrogation cavity with a 208 , barrel full of $\rho=1.0 \mathrm{~g} / \mathrm{cm}^{3}$ sand and vermiculite ( $\mathrm{SiO}$ ).

The original pulse of neutrons dies out rapidly in the external detector with no measureable response left after 0.4 to $0.5 \mathrm{~ms}$. On the other hand. thermal neutrons dieakay in the interrogation cavity with a half-life of about $0.76 \mathrm{~ms}$. (A lining of cadmium and boron neutron shielding totally isolates thermal zeutrons from the external detector.) Thus. the interrogation pulse lasts a long time in the interrogation cavity and can induce thermal neutron fissions in any fissile material present in the waste barrel. Prompt fission neutrons (hard spec trum) from such reactions then propagate to the external detector where they are recorded.

Figure 18 shows the measured response for a $200-\mathrm{s}$ interrogation period for samples of varying ${ }^{216} \mathrm{U}$ mass

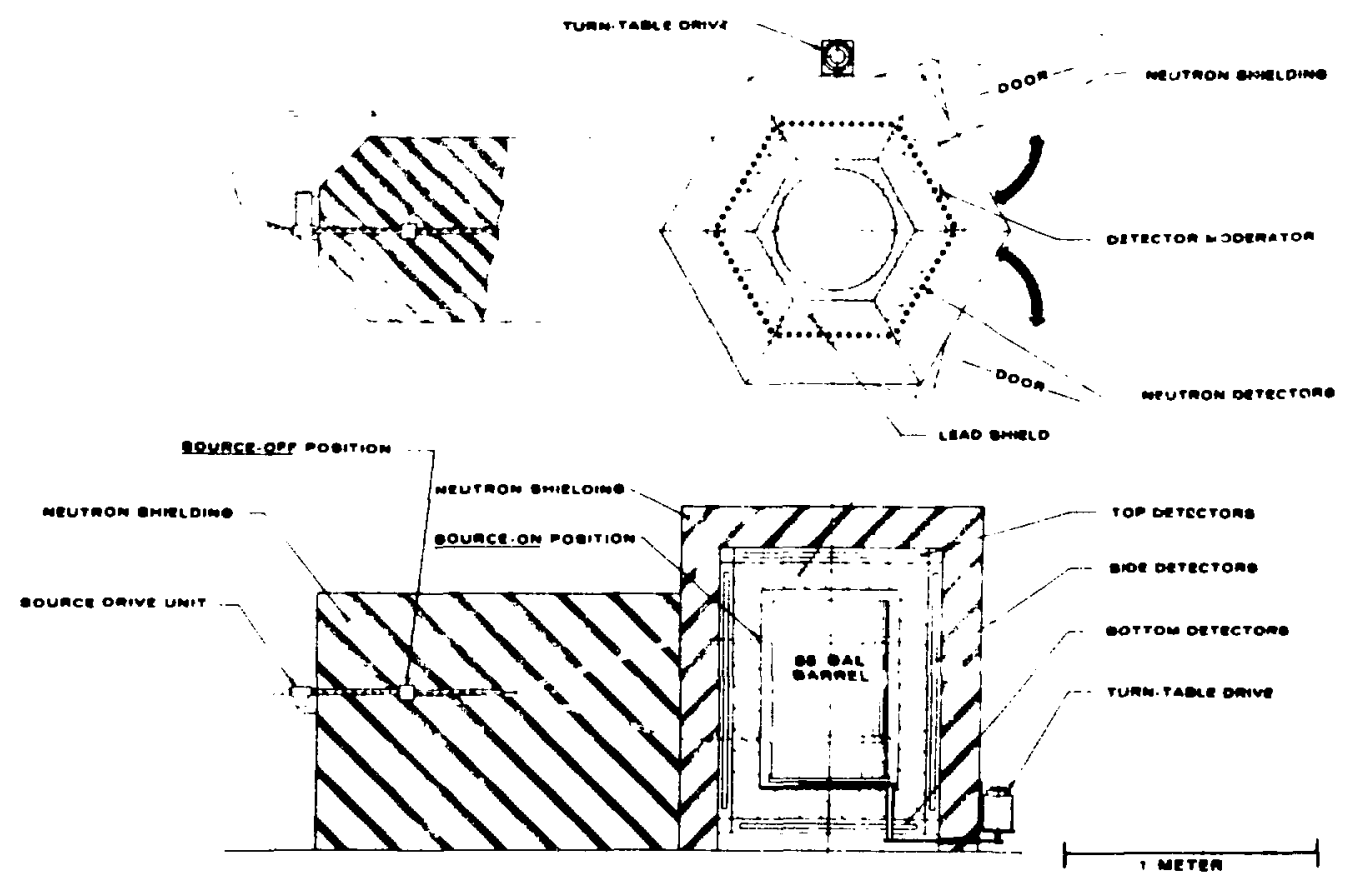

Fig. 15.

Conceptual design of 208- $\ell$ barrel size " Cf Shuffler System. 


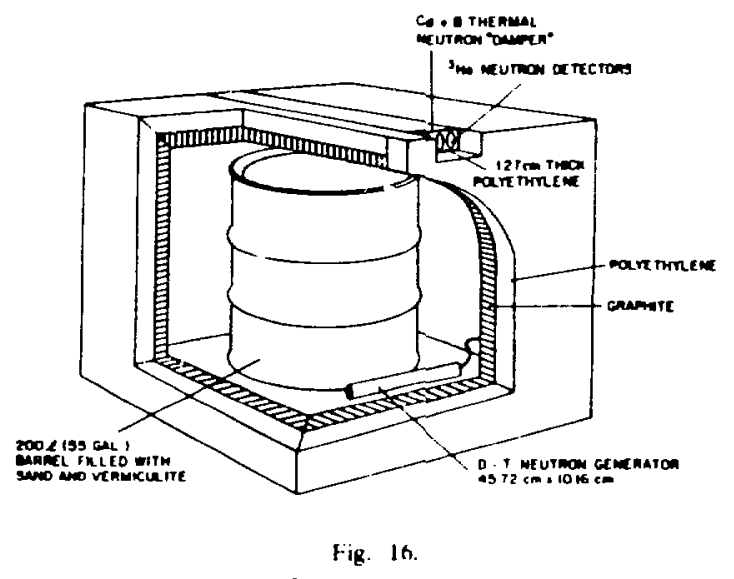

Schematic drawing of the prototype differential dienus technique interrogatun cavity and detectur

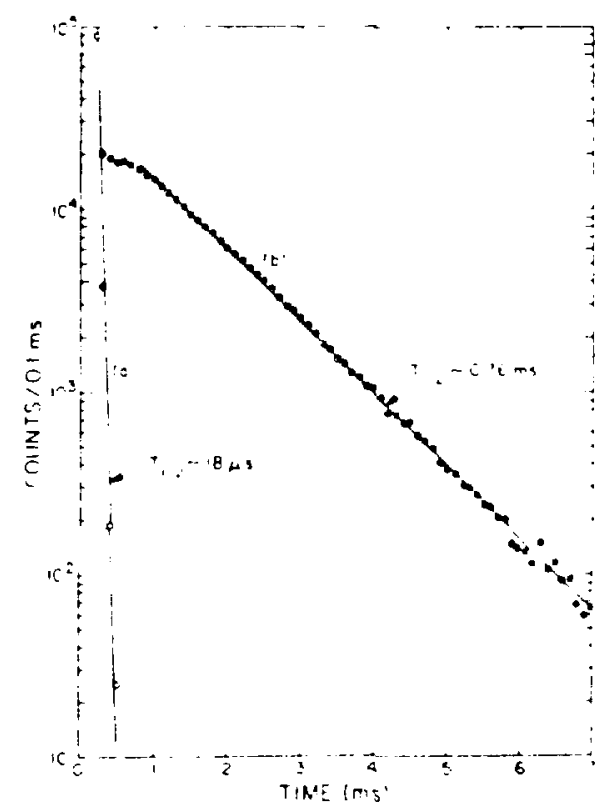

Fig. 17

Pulsed neutron dieau ay lime data for (a) external deterior and (b) interrogation casits.

placed within the sand-vermiculite illed harrel. A linear response as a function of " $U$ mass was observed, with an indicated $3 \sigma$ detection limit of about $3.5 \mathrm{mg}{ }^{23 !} \mathrm{U}$ for this prototype system. Additional studies ${ }^{20}$ have shown a uniform (to $+10 \%$ ) interrogation nux profile throughout the volume of the barrel as well. In other words. this

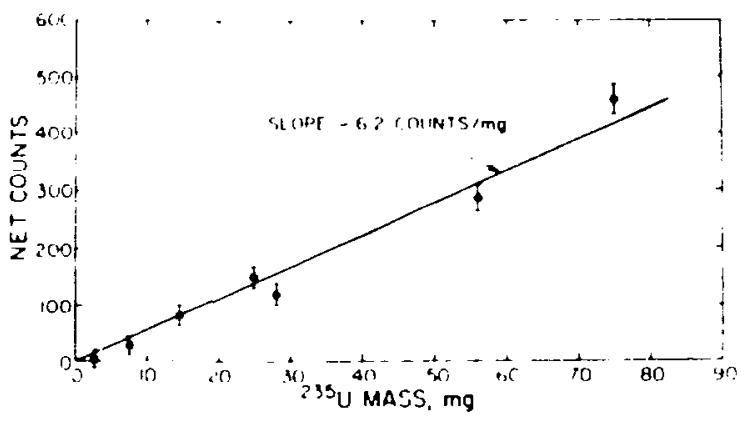

Fig. I8.

1. aperimental response (100), data collectlon timkes of dif

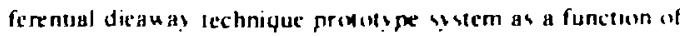
I maw

lechniyue shous great promise for the assay of fissle materaal an hus level. high densily wastes

Matrices consisting of high hydrogen density sludges or conciete will undoubtedly pose technical problems for some or all of the three techntuues discussed above Potenual correcuons to the analys of this type of data do exist. If the matrix is known. standards or other techniques can be used to correct the analysis for the influence of the matrix. In particular, the DDT method invoives the use af an interrogating flux monstor withon the interrogatum caitly." Measurements done to date induate that as the interrogating flux is absorbed of attenuated by wasle matrix. the thermal neutron flux throughout the cavily is proportionately reduced. Thus. by simply dividing the external detector response by the internal cavty fux monitor. one effectuely obtans an assa! that compensates for matrix effects

\section{Passive Neutron Assay Techniques}

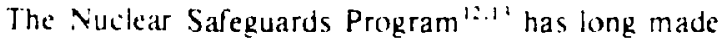
extens ve use of passive neutron coincidence techniques to quancify : ${ }^{\text {su }} \mathrm{Pu}$ content in a great variety of applica trons. With a known ${ }^{211}$ Pu isotopic ratio for the material being assayed. a complete total plutonum mass is simply calculated. For the proposed use of the SPI Facility." the vast majoitly of the fissile content of the waste to be processed will consist of weapons grade plutonium $156 \%:+1 \mathrm{Pul}$. In this sttuation. passive neutron coin cidence counting techniques may play a large role.

A Hell designed" 208 , barrel-size passive neutron coincidence counting system is in the final design stage at 
LASL. Witn "t (when the system is properly asielded from the cosmic-ray background). one can obtain a plutonium assay sensitivity of about $100 \mathrm{mg}$ for $5.6 \%$

$\therefore$ Pu content material in a $300-\mathrm{s}$ assay.

In addition. work is progressing on a crate-size passive concidence detector at L.ASL." When completed and accompanied with appropriate cosmic ray shielding. this detection system will have the capability of assaying $121.92 \mathrm{~cm}(48$ in.) $\times 121.92 \mathrm{~cm}(48$ in.) $\times 213.36 \mathrm{~cm}$ $(8.4 \mathrm{~m} .1$ crates to an assay sensitivity of ahout $50.100 \mathrm{mg}$ plutonium (5 $6 \%{ }^{2+1}$ Pu content) in a $1000 \mathrm{~s}$ assay period. Depending on the physical size of the waste containers at the SPI Facility. one or the other of these passive ivstems may be useful.

\section{SPI Facility Input Screening}

Waste screening will prevent many potental criticality problems. We recommend that it be based on assay measurements done before the waste enters the final process stream in the SP! Facility. We also recommend that such screening use the pulsed neutron generator DDT system. No matter what size the waste containers are. an applicable DDT system will be available within a fell years.

This preliminary screening would sort waste into the broad categories of (1) average TRU content, waste that has an acceptable fissile content: (2) low TRU content. waste that is essentially fissile free (to be regarded as an asset and kept separate for blending purposes): and (3) high TRU content, waste that has an unacceptably high fissile content.

At this point the high TRU content waste fraction should be subjected to a detailed fissile lump analysis. which may be obtainable with a spatially sensitive passive neutron measurement proposed as part of the large crate-size passive neutron detector. "An x.ray anaiysis combined with one of the passive and $/$ or active neutron measurements should also reveal the presence of a fissile lump. If a package containing a high TRU content contains a fissile lump. special handling and disposal is required. Unaer no circumstances should a lump ( $\geq 200 \mathrm{~g}$ of fissile material in a single piece) be allowed to enter the SPI Facility. The potential for criticality. even with the preventative measure of $\mathrm{B}_{2} \mathrm{O}_{3}$ poisoning. is too great to think of processing it routunely through the slagger. The sudden introduction of a large lump could result in a very rapidly developing criticality hazard. It is an anomaly and must be processed separate ly.

If the high TRL package does not contain lumps ot significant mass. then the package can be blended with the appropriate volume of the low TRL: fraction to generate an acceptable average TRL mix that can then be introduced ately into the SPI Facilit!.

The prelimmary creening phase is not a high quality assay measurement: $.50100 \%$ quality is adequate. This can be done ery rapily 1. 100 s for package uf to and including (rate size) and need not introduce ant significant tume delays in the overall processing. A more accurate (better geometry, better matrix compensation. etc. lassay meaturement for the input output considera tuns is hest done with the final blended SPI Facility input material.

\section{ASSAY OF PRODUCT SLAG CASTINGS}

If $1.0,10:$ ut frattion of $B: O$, is added to the SPI Facility uaste input. a farly accurate assay of the final $41.44 \mathrm{~cm}(3 \mathrm{~h}$ in. ) diam, $30.48 \mathrm{~cm} / 12 \mathrm{~m}$. $)$ thick. P $2.83 .0 \mathrm{~g} \mathrm{~cm}$. slag castung is obtanable by smpic cotat neutron colinting. (Refer to Table IX.) The known B:O. content of the slag casting should generate a farts

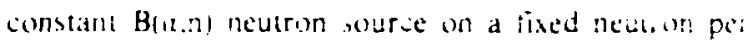
alpha parucle basis. This is baseci on the fact that thick target neutron yeids are not much different for the different apha particles that exist in the typical TRL wastes the SPI Facility will be processing that is, the L: Pu, and Am isotopes). Thus, the final stag casting neutron output will be a quantitative indication of its total TRL content.

If a total lissile content is desired. We recommend an active neutron measurement. Considering the expecied uniformity of the final produch any of the techniques discussed earlier could provide this assay. This measure ment will be the castest and by tar the most accurate of all the measurements performed at the SPI Facility. We do not see a need for lag grab sample assays. The slag casting can be more than adequate! assayed with presently known techniques. 


\section{CONCLUSIONS, RECOMMENDATIONS, AND COST ESTIMATES}

\section{A. Sonclusions}

We conclude on the hasis of this study that the proposed SPI Facility will have a minimal criticality hatard associated with its operation if a three level srilicality has ard prevention program is implemented. The three le.els of the program are as follows.

1. A prescreening $150100 \%$ accuracy. acule neutron assay of all incoming wastes is performed before they enter the SPI Facilit! processing stream. On the basis of this prescreentng into three broad categories leach atcgory to cover a factor of 310 or greater in fissle material concentratum). only an average fissile concen tratuon waste stream is processed by the SPI Facility. No stenticant fissile lumps or high concentration fisste materials are allowed into the SPI Facility. This prevents a iapid! developine iriticalit! hazard under most situ itions.

2. An approximate $10 \times 10^{2}$ wt fraction of $B_{2}, O_{1}, 10 r$ cyumaleni neutron pousons mixture is added uniformly to all waste. This sienificantly improves the criticalit! safet! w hle not ssgnificantly impactung processing volume or "Nerall SPI Facilit: economics.

: Drect cricalit hazard monitors are installed around the drying. pyrolysis. and slag forming regions and an! wher structure of the SPI Factity wath a potential critucalit! hazard. These monsiors should the hased on passive neutron counting using an existing deiectur design. An adjunct actue neutron system can be provided for monituring the build up of fissile isotopes.

We feel these three independent criticality hazard prevenuon measures will lower the criticalit! hazard a an acceptahly low level. At the same ume. these three sirategies do not add significantly to the cost or efficien $\because$ of the operation of the SPI Facility.

\section{B. Recommendations}

Fach of the three measures recommended requires more detasled siudy before actual start up of the SPI Facilit. It is cour judgment that the facility parameters the size and shape of the drying and pyrolysis regions: composition of waste: detailed incinerator properties such as lemperature and $B_{:} O$, distributions expected: and mant wher tactors need or bi quanufied heyond the present study. The final system will probably be some what difterent from that used in this study.

\section{Cost Estimates}

Recommendauons of specific instrumentation for the SPI Facili! are based on the current (February 1980) state of the art technology and on the authors. profections of what pertunent developments are likely to occur wi the next feu years.

1. The direct criticality monitors should be based on ': te polyethylene open faced sandwich proportional couriter ystems. A separate system will be required for cach of the drying. pyrolysis. and slag regions. This is based on the MCNP calculational results that showed neutronic decoupling of these regions. Some develop ment of these systems is required. chrefly. experimen tai calculational determination of exact size require ments. as well as a more detalled study of the false alarm optumal sensitivity problem. We estimate that monitur development costs will be about $\$ 200 \mathrm{k}$ in 1980 Jollars. Fquipment costs (these are more uncertain because exact detector sizes must be determined) for three separate systems with associated alarming equp ment will likely be in the $\$ 300 \$ \$ 00 k$ range 11480 dollars. This cost does not include the price of any SPI Facilit! ysiem shutdoun equipment. The active neutron additun discissed in the text would add about $\$ 50 k$ io the cost of each ststem.

2. For the prescreening phase. we recommend an actue neutron istem. specifically. the DDT system hecause of th more rapid assay capability. We assume that this ystem's developrnent will occur independently. of the SPI Facilut needs so that no developmental costs are included. IIf more rapid system development is required for the SPI Facility, additional funds for this would be required.) Projected costs for a single large DDT system / to handle any waste package cf $121.92 \mathrm{~cm}$ $148 \mathrm{in} .1 \times 121.92 \mathrm{~cm}(48 \mathrm{in}.) \times 213.36 \mathrm{~cm}$ (84 in.) or smaller! will be about $\$ 300 \mathrm{k}$. which includes a spare neutron generator and pulse transformer as well as all required personnel shielding. (The basic radiation hazard of this system is not large.) We assume that manual handling of waste packages with fork lifts or the like can he used. If fully automated handling is required. addi uonal costs will be incurred. 
3. For $x$ ray and other special measurements required for the fer "problem. uaste packages in the prescreen. ing phase. He recommend a sinall. low energy electron IInac. Vanan Associates of Palo Alto. Calıfornia, produce. un a commercial basis. such linacs for medical and uually control x ray work. A suitable 8.MeV machine (with pushbution $6 . \mathcal{A}$, and $10 \mathrm{MeV}$ options) is available from Varian Associates (hinatron 2000 ) for abou! $5300 \mathrm{k}$ on an uperational basis. We recommend installing this in an outhulding ta dirt shielded. large diameter cement Iran culvert could be used to greatly reduce costs) rather than incorporaung it into the SPI Facilit:

4. A large passive neutron concidence system may be desirable as part of the "problem" waste package measurements. This could be used to independently jetermine plutonium mass and possibly :o provide lump detection and location. Because this system would be intended for use with relatively large plutonum masses 1.10 \& Pul. no elahorate cosmic ray shielding is re qured. He estumate a system enst inodevelopment costs included of ahoui $\$ 350 \mathrm{k}$

5 A separate land smaller) DOT astle neutron yhem would he required for final product slag casting dssa!. This sclem should cost ahout $\$ 200 k$.

6. For the hight! accurate $1510 \%$ atcuracy) biended waste assa! measurement done within the SPI

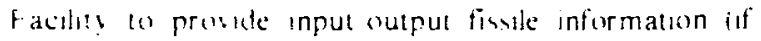
required. ue recommend a separate. specially destgned DDT ystem. For this purpose. special matrix com

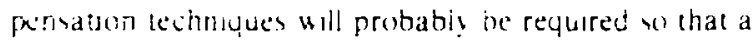
highly accurate asat can he ohtarned. We estunate a $\$ 200, \$ 3(1) \mathrm{k}$ debclopment tharge and a tinal design system cont of ahout $\$ 3($ ) ik

\section{ACKNOWIEDGMENT}

We thank D. R. Smuth and T. McLaughlin of the Los Aiamos Scontific Laboratory for several helpful sugges tuons and for revieuing the manuscript

\section{REFERENCES}

I. "L'se of Burosilica:e Glass Raschig Rings as a Neutron Absorber in Solutions of Fissile Material." American National Standard. ANSI V16.411971).

2. LASL Group $X 6$. W. L. Thompsm. Ed. "MCNP - a General Monte Carlo Code for Neu tron and Phuton Transpor." Los Alamos Scientific Laburatory report LA T:96 M. Rev. November 1474).

3. Karjer tengineers. Inc.. "Preliminary Criticality Evaluation of SPI Gastier and Secondary Combus tion Chamber." Idaho National Engineering Labo ratory report 79 24. R (April 1979).

4. Kırk MeKinie! EG\&G Idaho. Inc. prikaie com munication. Volember 19?9.

5 "Gastfier Design Concept," The Ralph M. Parsons Company projed number 961 ()06-80. Urawng number nlo06 D 1000001 (September 27. 19?4,

6. "Secondary Comtuston Chamber Gineral Ar. rangement." The Ralph M. Parsons Compas

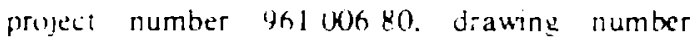
61006 D 20000 01 iseptemter 27. 1479).

7. H. 1. Atwater, Los Alamos Sicentutic Lahiratory. priale sommunicabon.

8. F. dethoffman. "Siaustical Aspects of Pile Theory." The Sicince and Engineering of Pucleor Power. id. II. C. Goodman. Fd. Adulison Wesle! Fublish

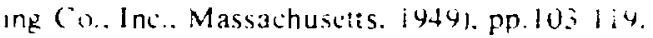

9. J. Ormudif. "Prompl Yeutron Perrats an Metal Crntciat issembites." Yuc!. Sol and Eng. 2. $\$ 50$ (1457).

10. S. H Vegurs. Jr. and E. B. Nieschmidt. "Pre !munar! Insest!gatuon of a Criticalıty Monitorung Technulue for a Transuranic Waste Incineratos." Idaho Natuonai Fnginesing Laboratory repors TRFF: 128: Ocwher 19781 .

11. R. H Augustson iand T. D. Reilly. “Fundamentals af Passibe Nundectructive Assay of Fissonable Material." Lis danoos Scientific Laboratars report I.A sns I M (September iy?4).

I2. N. Fussin. M1 L. Evans. H. O. Menlove, and J. E. Suanson. "Neutron Considerse Counters for Plutomum Mcasuremerts." J. Inst. Nucl. Mater. Manags. INMM! VIL. 13 (Sumner 1978). 
13. K. P. Lambert and J. W. Leake. "A Comparison of the F.D.C. and Shift Register Neutron Coincidence Systems for ${ }^{: \$} \mathbf{P u}$ Assay,." 3. Inst. Nucl. Mater. Manage. INMM VII. 87 (Winter 1978 1974).

14. E. J. Doudy, C. N. Henry. A. A. Robba. and J. C. Pratt. "New Neutron Correlatıon Measurement Technique for Special Nuclear Maierial Assay and Accountability." Proceedings of the International Symposium on Nuclear Material Safeguards. Vien na. Austria. October 26,1978 (IAEA. V'ienna. May 1974). Foi. II. pp. $125 \quad 136$.

IS. C. D. Ettridge, E. J. Doudy, C. N. Henry, and D. R. Millegan. "A Microprocessor Based Neutron Count Moment Logic Module for Special Nuclear Material Assay by the Neutron Fluctuation Mieth id." Proceedings l:SARDA Fir Annual Sym posium on Safeguards and Nuclear Material Man agement. Brussels. Belgium. April 25 26, 1974 (Brussels. 1979), ip. 320324.

16. F. J Dowdy. G. E. Hansen. A A. Robha and J. C Pratt. "Effect of $(a, n)$ Contaminants and Sample Muluplication on Statistical Neutron Correlation Measurements." Proceedings ESARDA Secund An nual Symposıum on Safeguards and Nuclear Mater al Management. L. Stanchı. Fd., Edinhurgh. Scodand. March 2628.1980 (Edinburgh. 19801. pp. 354.363 .
17. W. F. Kunz. J. D. Atencio, and J. T. Caldwe!.. “A I nCi.g Sensitivity Transuranic Waste Assay Sys tem Using Pulsed Neutron Interrogation." submitted to the Twenty first Annual Meeting of the INMM. Palm Beach. Florida. June 30. July 12.1980.

18. T. W. Crane. "Measurement of Pu Contamination at the $10 \mathrm{nC}$ g Level in 55 Gallon Barrels of Sold Waste with a "Cf Assay System." Proceedings of the International Meeting on Monitoring of Pu Contaminated Waste. J. Ley. Ed.. Ispra. Italy, September 25 28. $147411 \mathrm{spra}$. 1480). pp. 21:226.

14. M. R. Cittes. "Applicatiori of Lirear Accelesator Technolagy to the Detection of Trace Amounts of Transuranics in Waste Barrels," submitted to ti.e Symposium on the Management of Alpha Contaminated Wastes. Vienna. tustria. Jiane 2 h. 1480.

20. (i. Rohert Keenin. Ed.. "Nuclear Safeguards Re search and Development Program Status Report. Octoter December 1479." Los Alamus Scientulic Laboratory repor LA 8241 PR IMat 19801.

21. J. T. Calducil, "High Densut! Waste Assay: Large Crate Countung va Passive Neutron Couniaig." submitted to the Symposium on the Management of Apha Contammated Mastes. Vienna. Ausma. June 20. $14 \times 11$.

\section{APPENDIX SPI FACILITY GEOMETRY FOR MCNP}

The MCNP code requires an explicit description of all surfaces in the geometrical model. This apperidix sup plies this information for the SPI Facility, excluding all secondary structures. Figures $A \cdot 1-A 31$ are a com prehensive set showing the incinerator in the $y z, x z$, and $x y$ planes. Cuts in the $y z$ plane at important $x$ positions are shown in Figs. A 1-- A 6: cuts in the $x z$ plane at important $y$ positions are shown in Figs. A 7-A 19: cuts in the $x y$ plane at important z positions are shown in
Figs. A 20 A 31. The small numbers appearing on the figures are surface numbers as required by MCNP to describe the geometry. Table A I guves a complete listing of all the surface needed to describe the geometry. These are included for completeness and for the reader who want (1) know the detalls of the geometry. These surface cian be interpreted by referring to Ref. 2. 


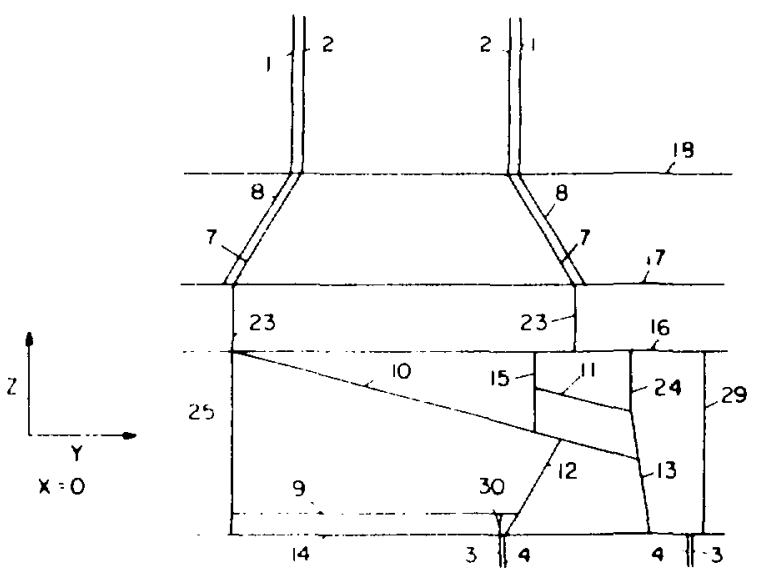

Fig. A-1.

View of the geometrical model of the SPI for the MCNP calculations. This is a cut in the $y$ a plane at the point $x=0 \mathrm{~cm}$.

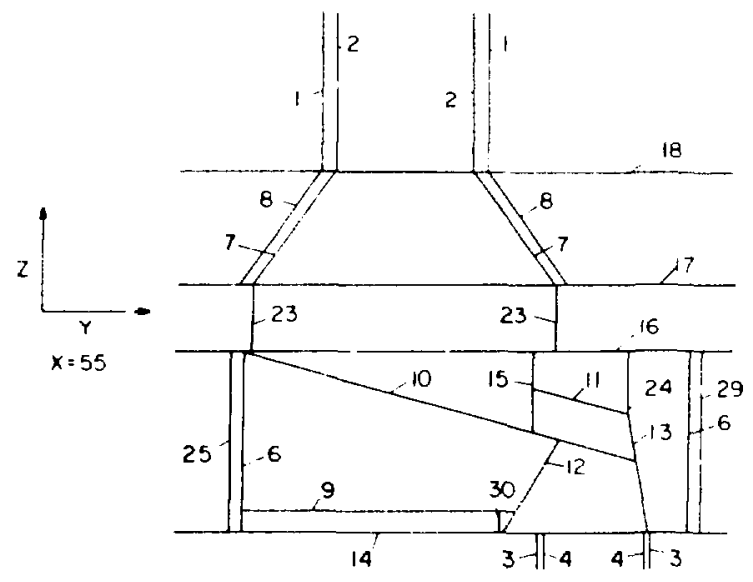

Fig. A.3.

View of the geometrical model of the SPI for the MCNP calculations. This is a cut in the $y z$ plane at the point $x=55$ $\mathrm{cm}$.

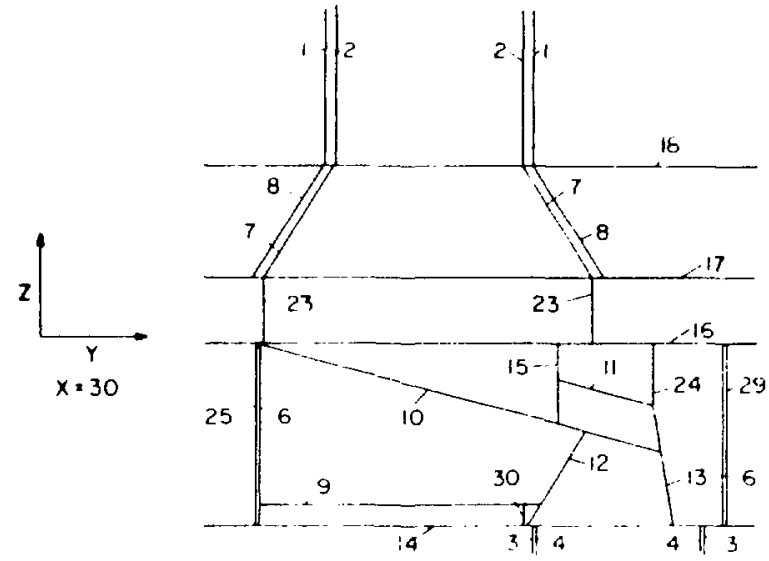

Fig. A 2.

View of the geometrical model of the SPl for the MCNP calculations. This is a cut in the yz plane at the point $x=30$ cm.

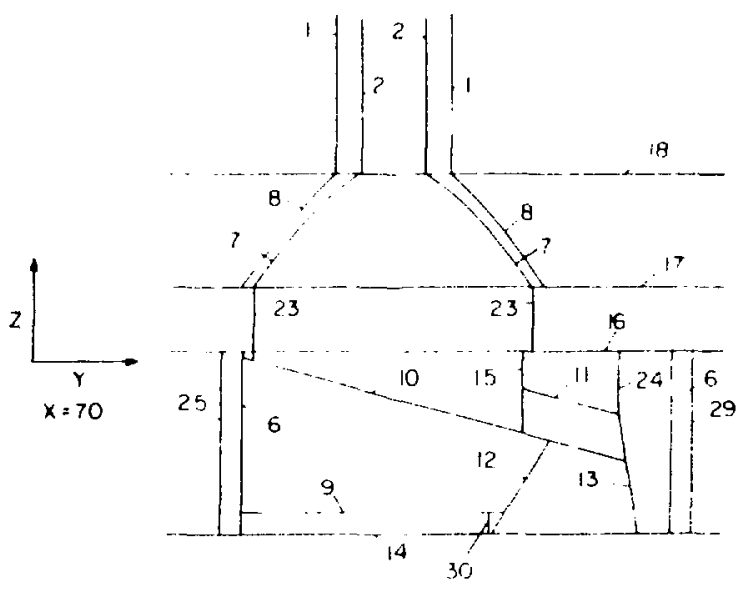

Fig. A.4.

View of the geometrical model of the SPI for the MCNP calculations. This is a cut in the $y z$ plane at the point $x-70$ $\mathrm{cm}$.

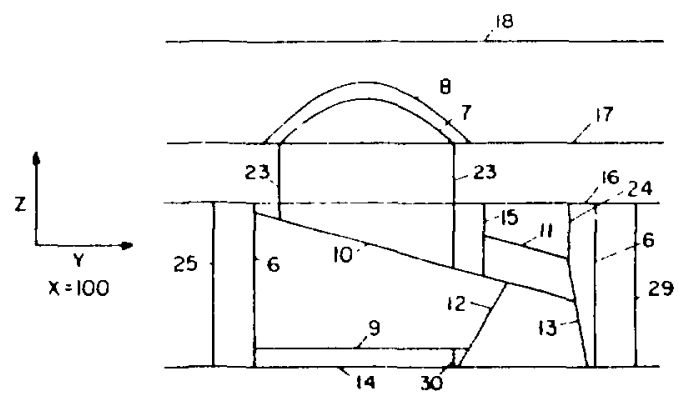

Fig. A-5.

View of the geometrical model of the SPI for the MCNP calculations. This is a cut in the yz plane at the point $x=100$ cm. 


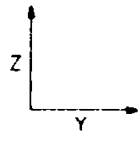

$x=200$

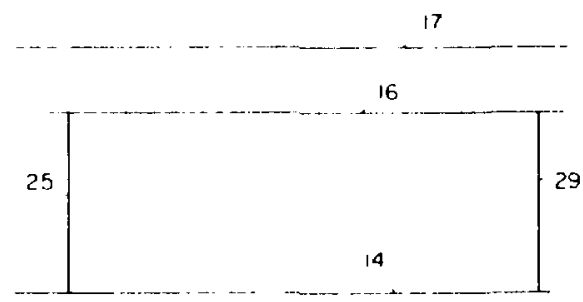

Fig. A 6 .

Vieu of the geometrical model of the SPI for the MCNP calculations. This is a cut in the $y$ plane at the point $x \quad 200$ cm.

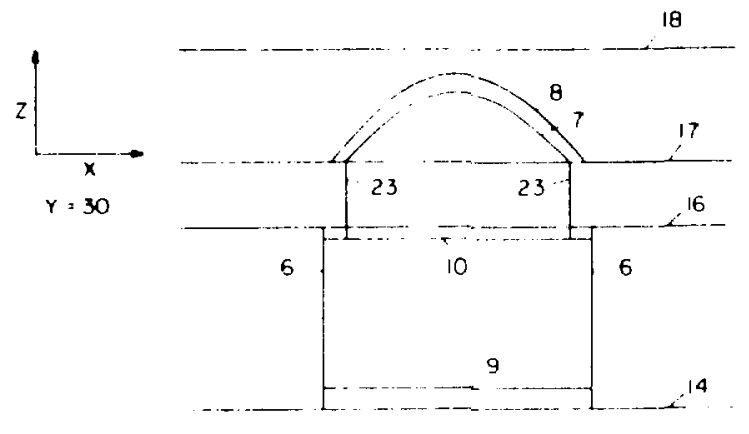

Fig. A 8 .

View of the geometrical modet of the SPI fur the MCNP calculations. This is a cut in the $x$ plane at the point $y \quad 30$ cm.

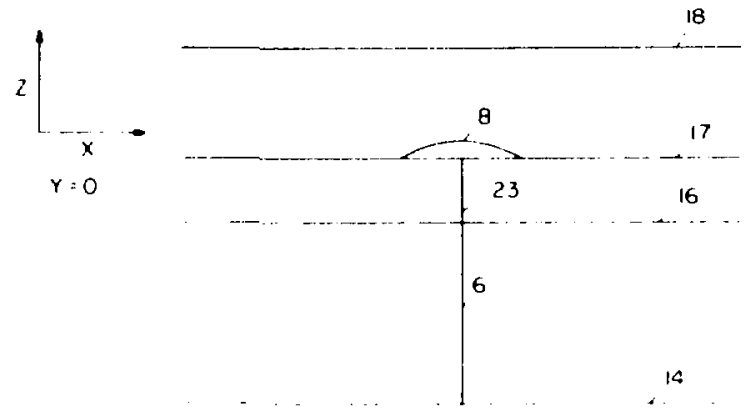

Fig. A 7 .

View of the geometrical model of the SPI for the MCNP calculations. This is a cut in the $x z$ plane at the point $y \quad 0 \mathrm{~cm}$.

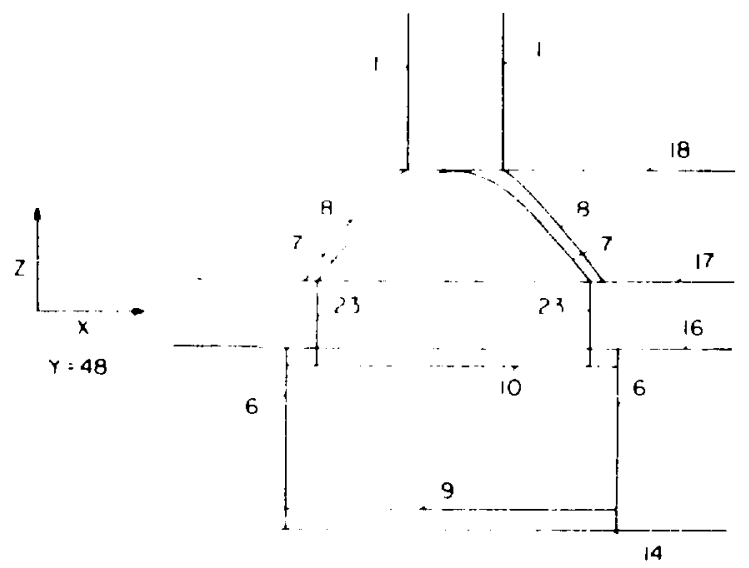

Fig. A 9.

Vien of the geometrical model of the SPI for the MCNP calculations. This is a cut in the $x z$ plane at the poins $y, 48$ $\mathrm{cm}$.

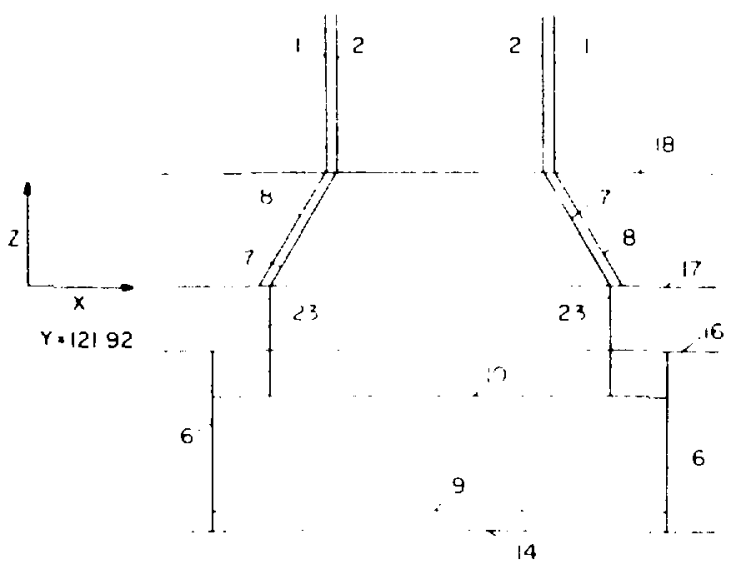

Fig. A 10.

Vicw of the geometrical modet of the SPI for the MCNP calculations. This is a cut in the $x z$ plane at the point $y=$ $121.92 \mathrm{~cm}$ 


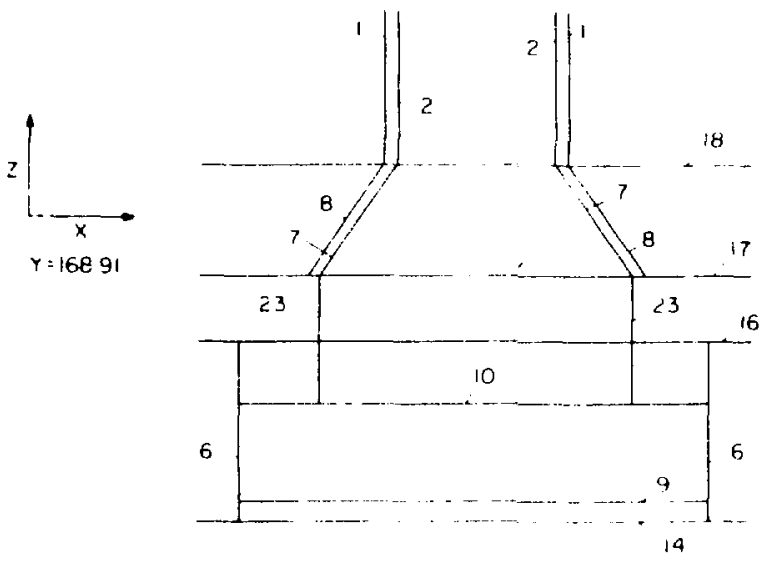

Fig. A. 11

View of the geometrical model of the SPI for the MCNP calculations. This is a cut in the $x z$ plane at the point $y$ $16891 \mathrm{~cm}$.
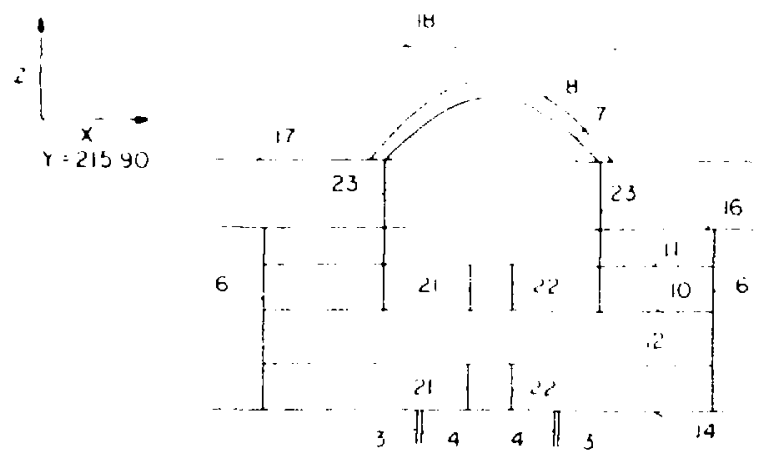

Fig. A 13.

View of the geometrical model of the SPI for the MCNP calculations. This is a cut in the $x z$ plane at the point $y$ $215.90 \mathrm{~cm}$.

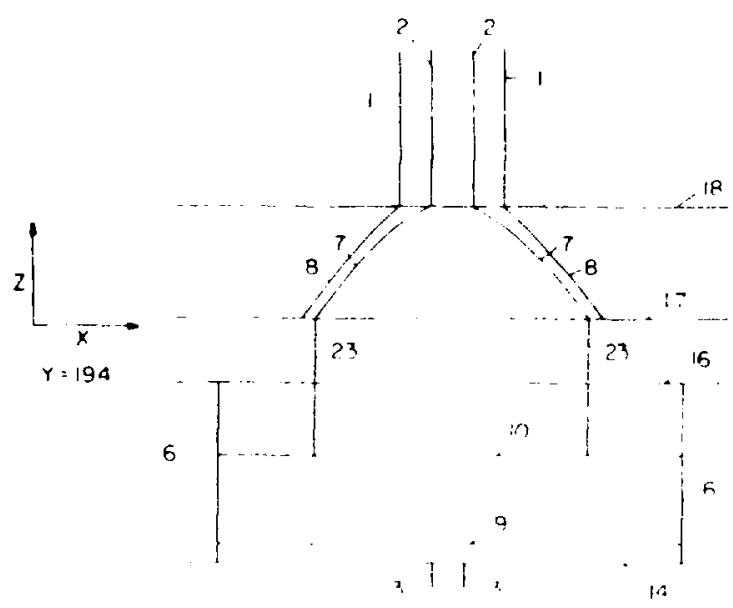

Fig. A 12.

View of the geometrical model of the SPI for the $:: C N$ N calcutations. This is a cut in the $x z$ plane at the point? 194 $\mathrm{cm}$.

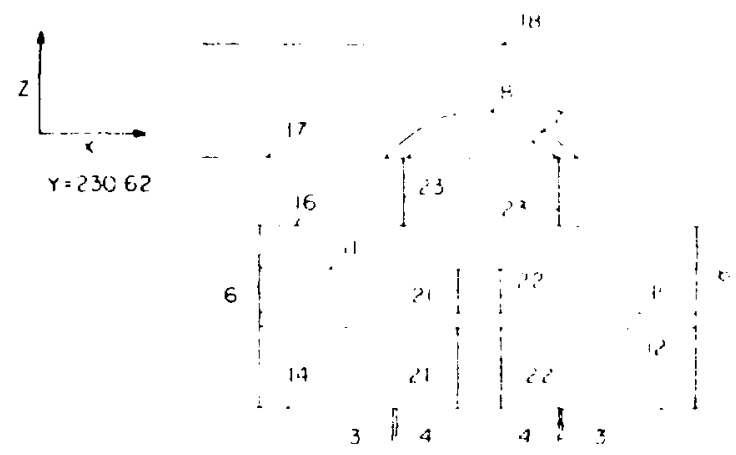

Fig. A 14

$\checkmark$ iet of the geometrical model of the SPI for the MCNI calculations. This is a cut in the $y$ plane at the point $y$ $230.62 \mathrm{~cm}$.

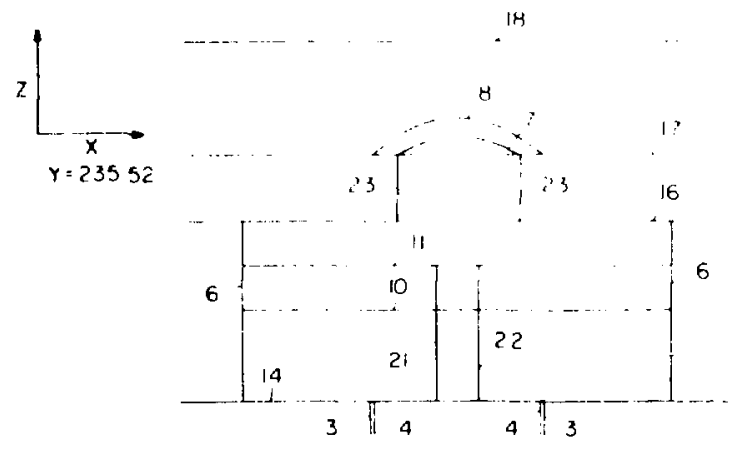

Fig. A 15.

View of the geometrical model of the SPI for the MCNP calculations. This is a cut in the $x z$ plane at the point $y$. $235.52 \mathrm{~cm}$. 

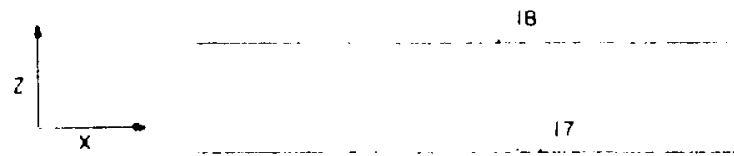

$Y=28437$
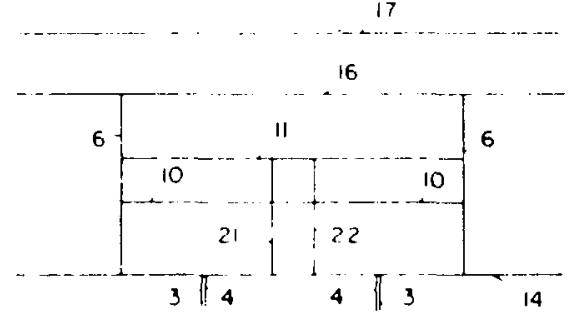

Fig. $A 16$.

View of the geometrical model of the SPI for the MCNP calculations. This is a cut in the $x$ plane at the point $y$ $284.37 \mathrm{cin}$.


Fig. A 18.

Vieu of the geometrical mudel of the SPI for the MCNP calculations. This is a cut in the $x$. plane at the point $y-330$ cm.
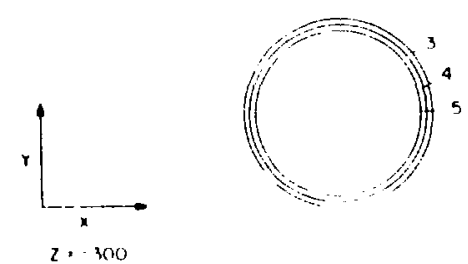

Fig. A 20.

View of the geometrical model of the SPI for the MCNP $\therefore$ alculations. This is a cut in the $x y$ plane at the point $z=-300$ $\mathrm{cm}$.

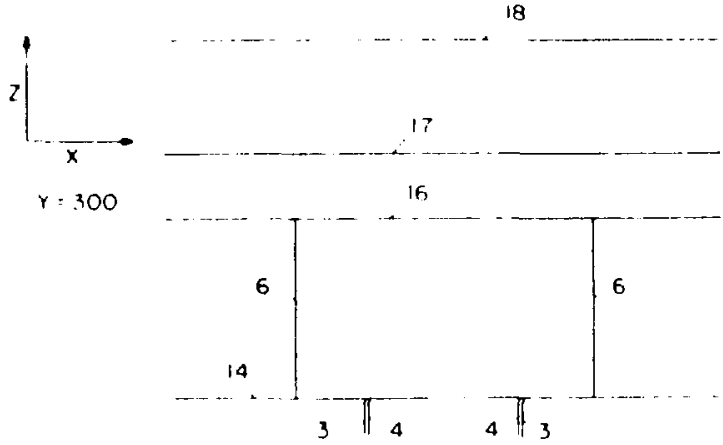

Fig. A 17.

View of the geometrical model of the SPI for the MCNP calculations. This is a cut in the $x \geq$ plane at the point $y \quad 300$ $\mathrm{cm}$.

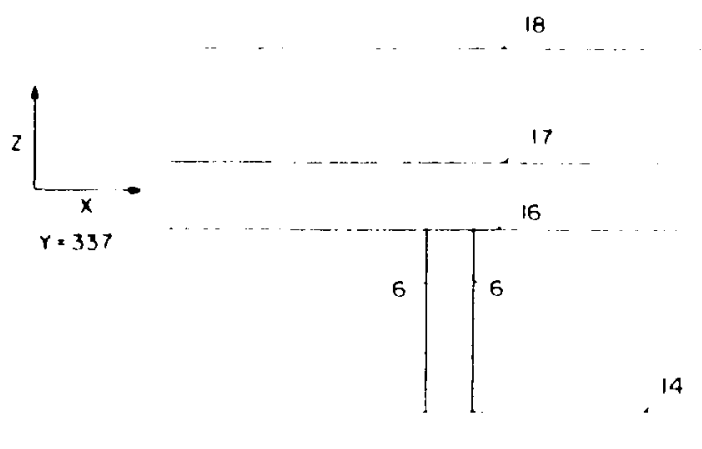

Fig. A 19.

View of the geometrical model of the SPI for the MCNP calculations. This is a cut in the $x 7$ plane at the point $y \quad 337$ cm.
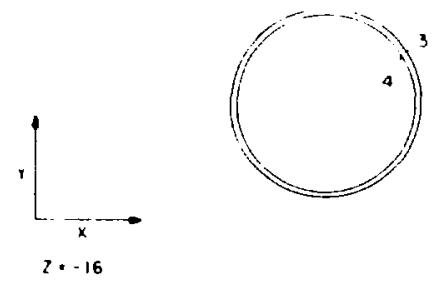

Fig. A 21 .

View of the geometrical model of the SPI for the MCNP calculations. This is a cut in the $x y$ plane at the point $z=-16$ $\mathrm{cm}$. 


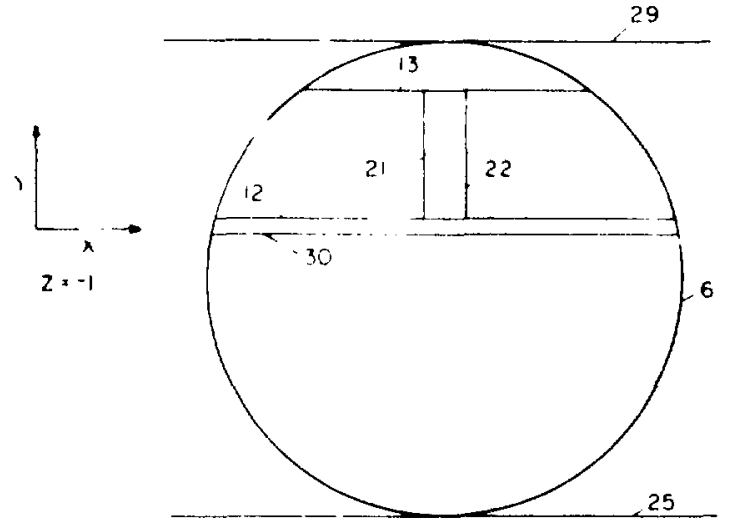

Fig. A.22.

View of the geometrical model of the SPI for the MCNP calcuiacions. This is a cut in the $x y$ plane at the point $z=-1$ cm.

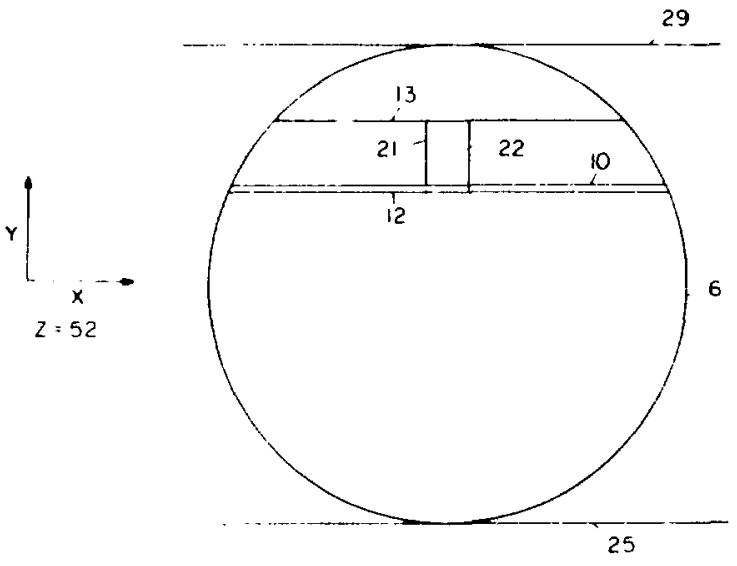

Fig. A-24.

View of the geometrical model of the SPI for the MCNP calculations. This is a cut in the $x y$ plane at the point $z=52$ cm.
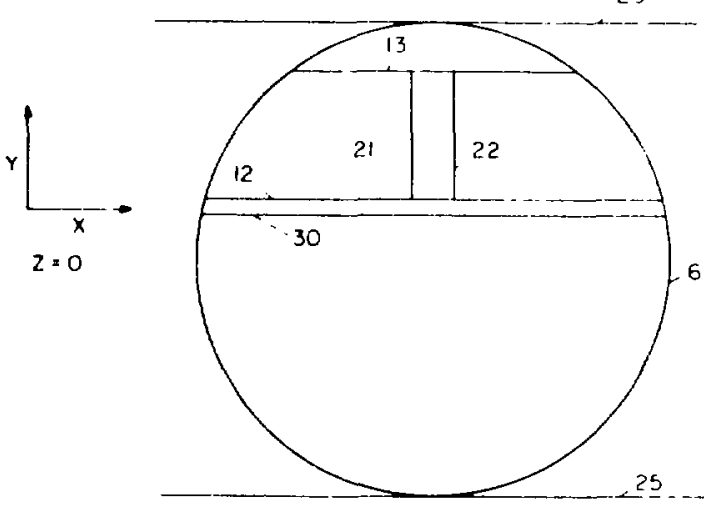

Fig. A-23.

View of the geometrical model of the SPl for the MiNP calculations. This is a cut us the $x y$ plane at the point $z=0 \mathrm{~cm}$.

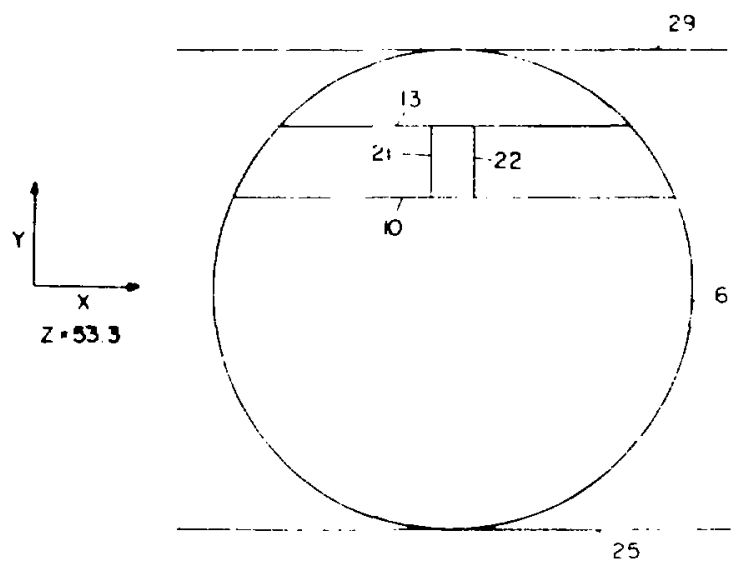

Fig. A-25.

View of the geometrical model of the SPI for the MCNP calculations. This is a cut in the $x y$ plane at the point $z=53.3$ cm. 


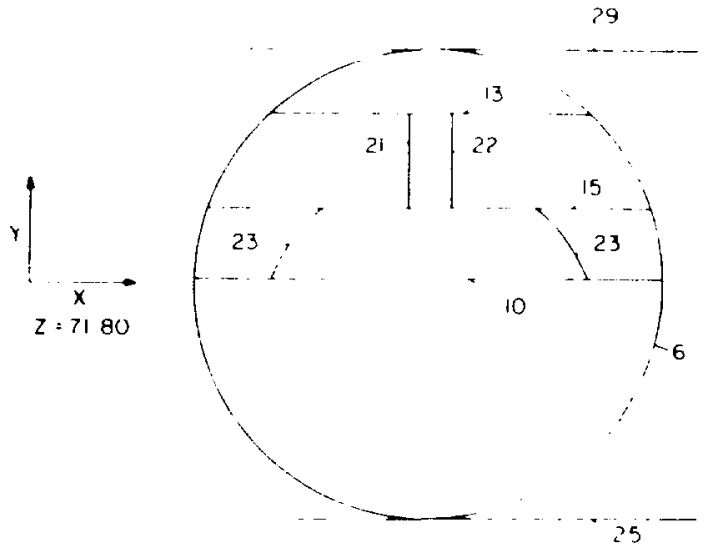

Fig. A 20 .

Vieu of the geometrical model of the SPI for the MCNP calculations. This is a cut in the $x y$ plane at the point $z \quad 71.80$ $\mathrm{cm}$.



Fig. A 28 .

View of the geometrical model of the SPI for the MCNP calculations. This is a cut in the $x y$ plane at the point 2 $116.45 \mathrm{~cm}$.


Fig. A 30

View of the geometrical model of the SPI for the MCNP caiculations. This is a cut in the $x y$ plane at the point $z=243$ $\mathrm{cm}$.

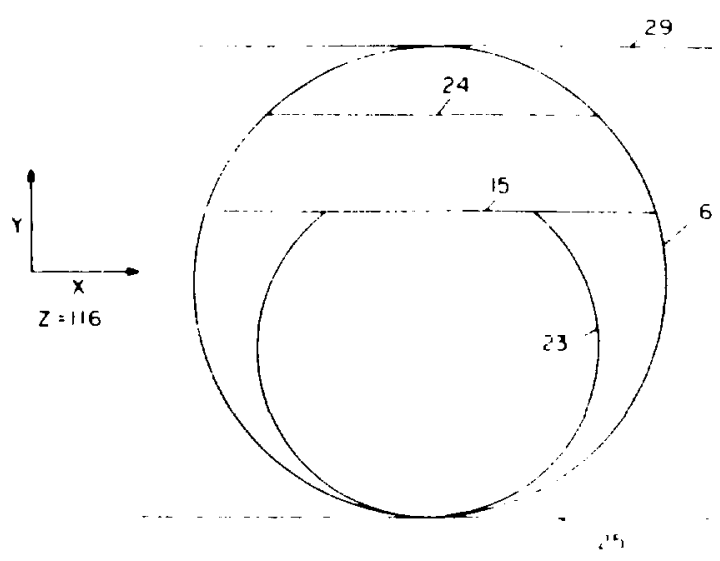

Fig. A 27 ,

View of the geometrical model of the SPI for the MCNP calculations. This is a cut in the $x y$ plane at the moint $z \quad 116$ $\mathrm{cm}$.

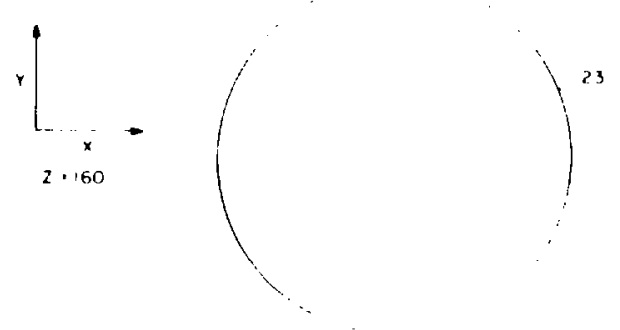

Fig. A 29.

View of the geometrical model of the SPI for the MCNP calculations. This is a cut in the $x y$ plane at the point $r \quad 160$ $\mathrm{cm}$.

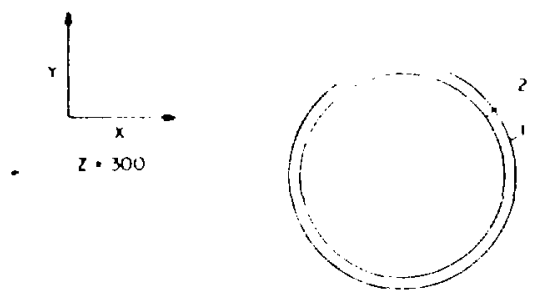

Fig. A 31 ,

View of the geometrical model of the SPI for the MCNP calculations. This is a cut in the $x y$ plane at the point $z=300$ cm. 
TABLE A-I

GEOMETRY OF INCINERATOR

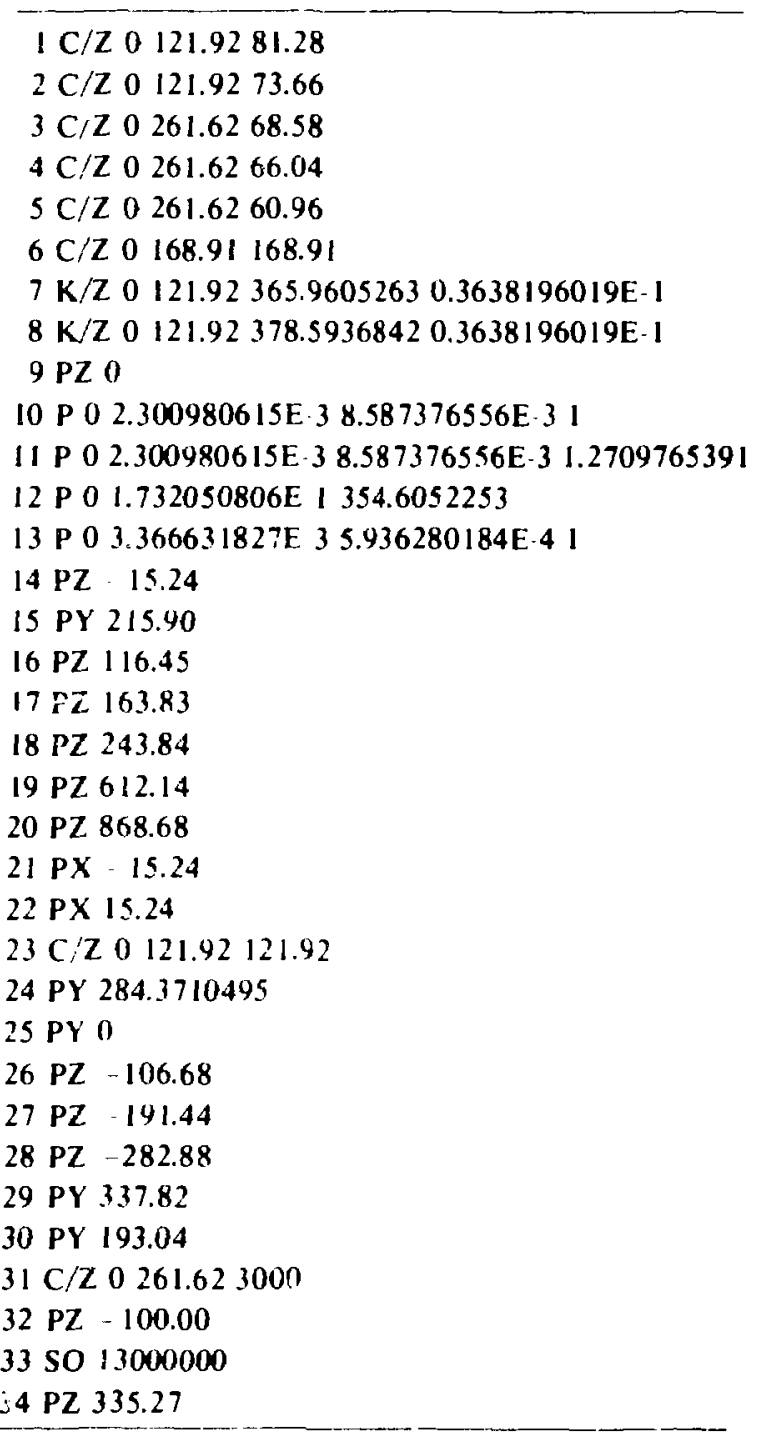

